\title{
SARS-CoV-2 nucleocapsid protein forms condensates with viral genomic RNA
}

\author{
Amanda Jack $\oplus^{1}$, Luke S. Ferro ${ }^{2}$, Michael J. Trnka ${ }^{3}$, Eddie Wehri ${ }^{4}$, Amrut Nadgir $\oplus^{5}$, \\ Xammy Nguyenla ${ }^{6}$, Douglas Fox $\oplus^{6}$, Katelyn Costa $^{7}$, Sarah Stanley $\oplus^{2,6}$, \\ Julia Schaletzky $\varpi^{4}$, Ahmet Yildiz ${ }^{1,2,5 *}$
}

1 Biophysics Graduate Group, University of California, Berkeley, California, United States of America, 2 Department of Molecular and Cell Biology, University of California, Berkeley, California, United States of America, 3 Department of Pharmaceutical Chemistry, University of California, San Francisco, California, United States of America, 4 Center for Emerging and Neglected Diseases, University of California, Berkeley, California, United States of America, 5 Physics Department, University of California, Berkeley, California, United States of America, 6 School of Public Health, Division of Infectious Diseases and Vaccinology, University of California, Berkeley, California, United States of America, 7 Press West Illustrations, Boston, Massachusetts, United States of America

*yildiz@ berkeley.edu

\section{Abstract}

The Severe Acute Respiratory Syndrome Coronavirus 2 (SARS-CoV-2) infection causes Coronavirus Disease 2019 (COVID-19), a pandemic that seriously threatens global health. SARS-CoV-2 propagates by packaging its RNA genome into membrane enclosures in host cells. The packaging of the viral genome into the nascent virion is mediated by the nucleocapsid $(\mathrm{N})$ protein, but the underlying mechanism remains unclear. Here, we show that the $\mathrm{N}$ protein forms biomolecular condensates with viral genomic RNA both in vitro and in mammalian cells. While the $\mathrm{N}$ protein forms spherical assemblies with homopolymeric RNA substrates that do not form base pairing interactions, it forms asymmetric condensates with viral RNA strands. Cross-linking mass spectrometry (CLMS) identified a region that drives interactions between $\mathrm{N}$ proteins in condensates, and deletion of this region disrupts phase separation. We also identified small molecules that alter the size and shape of $\mathrm{N}$ protein condensates and inhibit the proliferation of SARS-CoV-2 in infected cells. These results suggest that the N protein may utilize biomolecular condensation to package the SARS-CoV-2 RNA genome into a viral particle.

\section{Introduction}

The Severe Acute Respiratory Syndrome Coronavirus 2 (SARS-CoV-2) virus consists of a 30-kb single-stranded RNA genome packaged into a 100-nm diameter membrane enveloped virion. SARS-CoV-2 encodes for multiple proteins involved in viral assembly and propagation [1] and infects human cells by binding its spike (S) protein to the angiotensin converting enzyme 2 (ACE2) receptor on host cells [2-4]. While the majority of current efforts to treat Coronavirus Disease 2019 (COVID-19) have focused on targeting this interaction [5,6], not much work has been done to stop the proliferation of the virus in host cells following infection. 
supported by Dr. Miriam \& Sheldon G. Adelson Medical Research Foundation (AMRF) and the UCSF Program for Biomedical Breakthrough Research (PBBR). Experiments involving screening drugs against infected cells were funded by the Center of Emerging and Neglected Diseases at UC Berkeley, and through Fast Grants (part of Emergent Ventures at George Mason University). The funders had no role in study design, data collection and analysis, decision to publish, or preparation of the manuscript.

Competing interests: The authors have declared that no competing interests exist.

Abbreviations: ACE2, angiotensin converting enzyme 2; BS3, bis(sulfosuccinimidyl) suberate; CLMS, cross-linking mass spectrometry; COVID19, Coronavirus Disease 2019; CPE, cytopathic effect; CTD, carboxyl-terminal domain; EMCCD, electron-multiplying CCD; ERGIC, ER-Golgi intermediate compartment; FBS, fetal bovine serum; FDA, Food and Drug Administration; FDR, false discovery rate; $\mathrm{FISH}$, fluorescence in situ hybridization; FRAP, fluorescence recovery after photobleaching; HEK293, human embryonic kidney; HiLO, highly inclined and laminated optical sheet; hpi, hours postinfection; IDR, intrinsically disordered region; LC-MS, liquid chromatography-mass spectrometry; LLPS, liquid-liquid phase separation; M, membrane; MAVS, mitochondrial antiviral-signaling protein; MOI, multiplicity of infection; MS, mass spectrometry; N, nucleocapsid; NTD, N-terminal domain; PLD, prion-like domain; PS, penicillinstreptomycin; RTC, replication transcription complex; S, spike; SAF, spectral abundance factor; SARS-CoV-2, Severe Acute Respiratory Syndrome Coronavirus 2; SEC, size exclusion chromatography; SLIP, site localization in peptide; SR, serine/arginine-rich; TCID, tissue culture infectious dose; TIRF, total internal reflection fluorescence; UCSD, University of California San Diego; UTR, untranslated region; VLP, viral-like particle; VRNP, viral ribonucleoprotein; WT, wildtype; XIC, extracted precursor ion chromatogram.
Condensation of the viral genome into a virion is primarily driven by the nucleocapsid $(\mathrm{N})$ protein [7], which is the most abundant viral protein in infected cells [8,9]. A large pool of free $\mathrm{N}$ protein is expressed early in infection [10], and only a small fraction is transferred into mature virions [9]. The $\mathrm{N}$ protein accumulates at the replication transcription complex (RTC) $[11,12]$ where it enhances replication and the transcription of viral RNA $[13,14]$. The N protein also restructures viral genomic RNA into shell-shaped structures (approximately $15 \mathrm{~nm}$ in diameter), which contain approximately $12 \mathrm{~N}$ proteins and 800 nucleotides of viral RNA $[7,15]$. These viral ribonucleoprotein (vRNP) complexes form asymmetric "beads on a string" structures that then bind to the viral membrane $(\mathrm{M})$ protein on the surface of the ER-Golgi intermediate compartment (ERGIC) to trigger the budding of the vRNP complex.

The mechanism by which $\mathrm{N}$ remodels the viral RNA and packages it into a viral particle is not well understood. Recent studies proposed that the replication and packaging of viruses involve liquid-liquid phase separation (LLPS) [16-18]. Biomolecular condensation drives the formation of membrane-less organelles such as the nucleolus, centrosome, stress granules, and $P$ granules through a network of weak and multivalent interactions. Nucleic acids are involved in the formation of biomolecular condensates because they can scaffold multivalent interactions [19-21]. Coronaviruses are involved with phase-separated structures such as stress granules $[1,10]$ and replicate at dynamic clusters associated with the ERGIC, suggesting that phase separation may play a critical role in the replication and packaging of SARS-CoV-2.

Previous studies in positive and negative-sense RNA viruses showed that $\mathrm{N}$ proteins drive the formation of phase-separated condensates in the cytosol [22-25]. The N protein of SARS-CoV-2 also contains many of the characteristic domain features common in phase separating proteins. It contains a well-conserved N-terminal domain (NTD) and a carboxyl-terminal domain (CTD, Fig $1 \mathrm{~A}$ ), and $40 \%$ of its primary sequence is predicted to be part of intrinsically disordered regions (IDRs, Fig 1B). The NTD (amino acids 44 to 174) interacts nonspecifically with RNA and recognizes a nucleotide sequence in the $3^{\prime}$ end of the viral genome [13]. The CTD (amino acids 257 to 366) mediates dimerization [26], but the $\mathrm{N}$ protein can also self-associate into tetramers and higher oligomers $[27,28]$. The NTD and CTD are separated by an IDR that contains a serine/arginine-rich (SR) motif, which has been associated with phase separation in other ribonucleoproteins $[13,29]$. The $\mathrm{N}$ and carboxyl-terminal IDRs are less conserved but contain arginine- and lysine-rich disordered regions (Fig 1B), which may facilitate additional interactions with the negatively charged RNA backbone [30] and drive biomolecular condensation of RNA [31,32]. The N-terminal IDR contains a predicted prion-like domain (PLD, Fig 1A) that can potentially trigger protein demixing [13,29,33]. The carboxyl-terminal IDR of SARS-CoV N mediates binding to the $\mathrm{M}$ protein $[34,35]$. The $\mathrm{N}$ protein is highly positively charged (+24 in $\mathrm{pH}$ 7.4) [36], and the CTD and disordered regions also interact with negatively charged RNA and promote vRNP packaging [37]. The precise roles of these domains in the phase separation of $\mathrm{N}$ protein remain to be elucidated.

In this study, we purified the SARS-CoV-2 N protein from human embryonic kidney (HEK293) cells and observed that $\mathrm{N}$ protein forms biomolecular condensates with both homopolymeric and viral genomic RNA under physiological salt conditions in vitro. We also showed that the $\mathrm{N}$ protein forms liquid condensates in mammalian cells. Cross-linking mass spectrometry (CLMS) identified 2 regions flanking the CTD with interactions enriched within the condensed phase, and the deletion of one of these regions fully abrogated condensate formation in vitro. Together, our results indicate that the $\mathrm{N}$ protein phase separates with genomic RNA of SARS-CoV-2, which may play an important role in the packaging of new viral particles in host cells. 
A

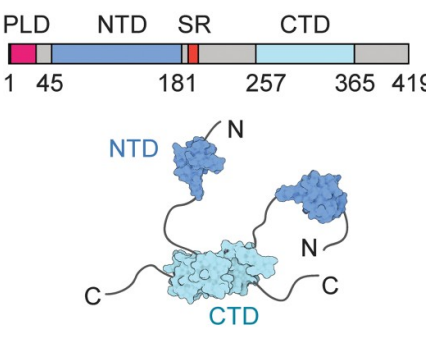

B

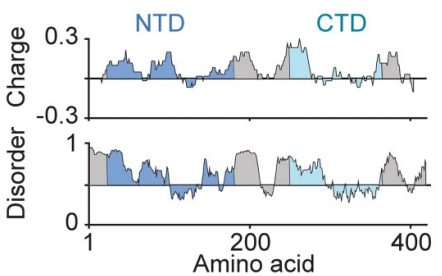

C
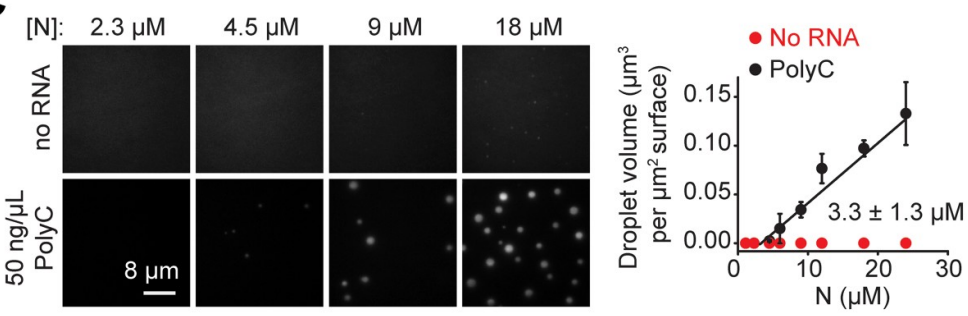

D
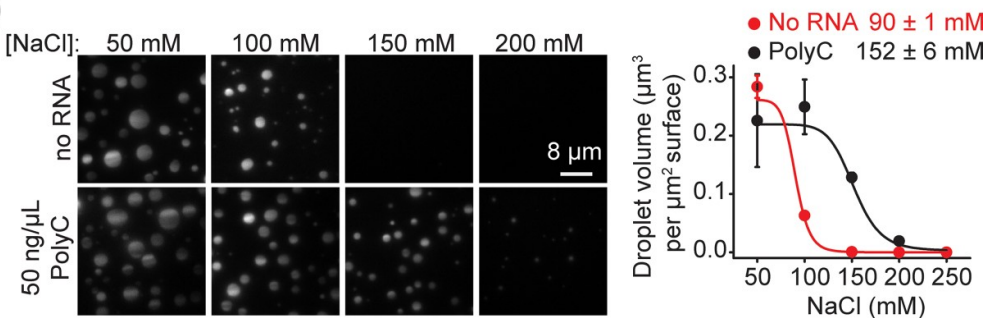

E
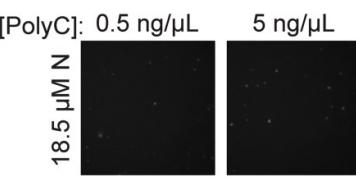

$50 \mathrm{ng} / \mu \mathrm{L}$
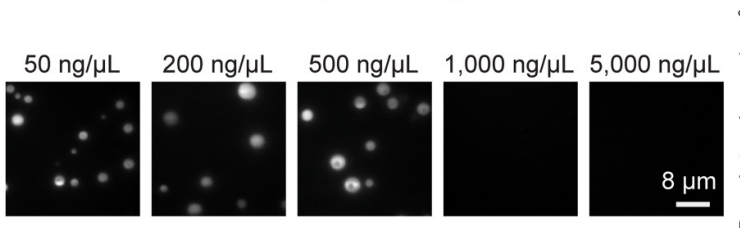

F

G
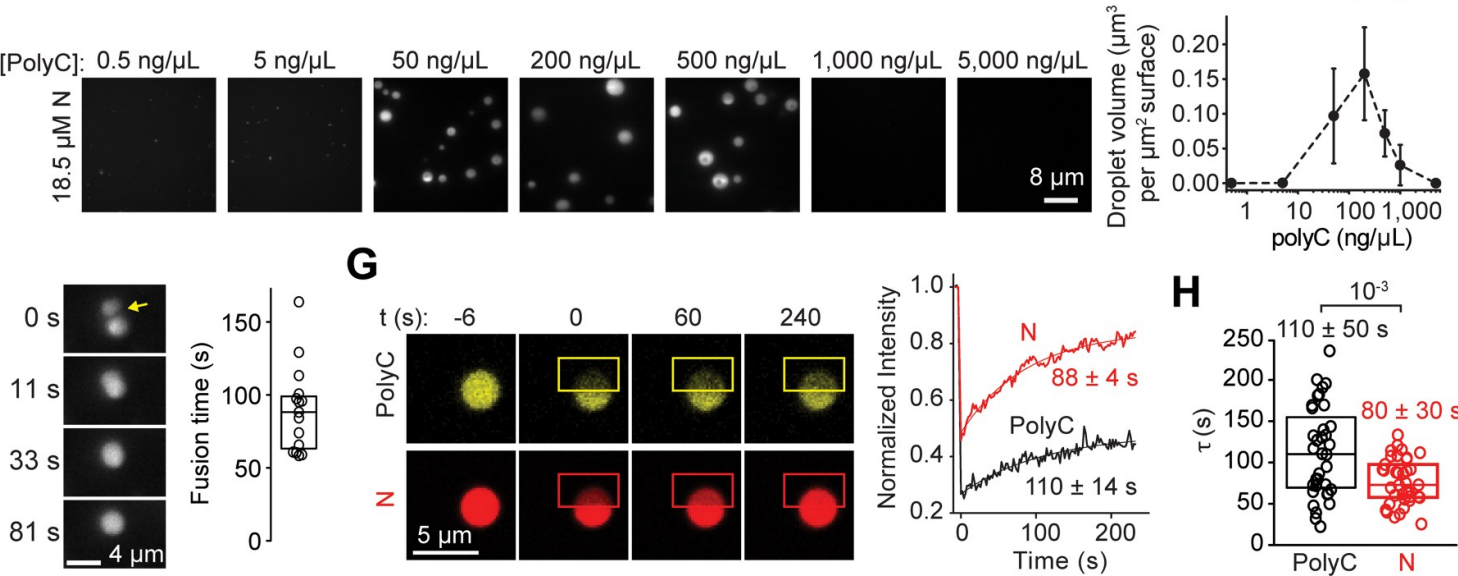

Fig 1. The SARS-CoV-2 N protein phase separates with RNA in vitro. (A) Domain organization and the schematic of the $\mathrm{N}$ protein dimer. (B) Sliding window plot of charge distribution (EMBOSS) and disorder prediction (IUPred2A) for the N protein. Charge y-axis represents mean charge across a 30-residue sliding window. Disorder prediction (1, disordered; 0 , ordered) was calculated using the "long disorder" setting, encompassing a 30-residue sliding window. (C) (Left) Images of the LD655-labeled N protein in the presence and absence of polyC RNA in $150 \mathrm{mM} \mathrm{NaCl}$. (Right) The total volume of N-RNA condensates settled per micron squared area on the coverslip with and without $50 \mathrm{ng} / \mu \mathrm{L}$ polyC RNA (mean $\pm \mathrm{SD}, n=20$ with 2 technical replicates). A linear fit (solid line) reveals $\mathrm{c}_{\text {sat }}$ ( \pm $\mathrm{SE}$ ), the minimum $\mathrm{N}$ protein concentration for condensate formation (see Methods). (D) (Left) Condensates formed by $24 \mu \mathrm{M}$ LD655-labeled $\mathrm{N}$ protein in the presence or absence of $50 \mathrm{ng} / \mu \mathrm{L}$ polyC RNA dissolve by increasing NaCl concentration. (Right) The total volume of $\mathrm{N}$ condensates settled per micron squared area on the coverslip with increasing salt concentration (mean $\pm \mathrm{SD}, n=10$ ). Solid curves represent a fit to a dose-response equation to determine $\mathrm{IC}_{50}( \pm \mathrm{SE})$. (E) The stoichiometry of the N protein and RNA affects phase separation. (Left) Example pictures show that Cy3-labeled $\mathrm{N}$ protein forms condensates with different concentrations of polyC RNA. The $\mathrm{N}$ protein concentration was set to $18.5 \mu \mathrm{M}$. (Right) The total volume of N-polyC condensates settled per micron squared area on the coverslip under different RNA concentrations (mean $\pm \mathrm{SD} ; n=20,2$ technical replicates). (F) (Left) The fusion of $\mathrm{N}$ polyC condensates formed in the presence of $18.5 \mu \mathrm{M}$ LD655-labeled $\mathrm{N}$ and $50 \mathrm{ng} / \mu \mathrm{L}$ polyC RNA. (Right) Fusion time of N-polyC condensates (mean $\pm \mathrm{SD}, n=15$ fusion events). The center and edges of the box represent the median with the first and third quartiles. (G) (Left) Representative FRAP imaging of an N-polyC condensate. The image of a condensate before the time of photobleaching (0 second) shows colocalization of Cy3-polyC and LD655-N in the condensate. Rectangles show the photobleached area. (Right) Fluorescence recovery signals of $\mathrm{N}$ and polyC in the bleached region. Solid curves represent a single exponential fit to reveal the recovery lifetime ( $\tau, \pm 95 \%$ confidence interval). (H) The distribution of fluorescence recovery lifetimes of $\mathrm{N}$ and polyC in droplets $(n=37)$. The center and edges of the box represent the median with the first and third quartiles. The $p$-value was calculated from a 2 -tailed $t$ test. Data underlying this figure can be found in S1 Data. CTD, carboxyl-terminal domain; N, nucleocapsid; NTD, N-terminal domain; PLD, prion-like domain; SARS-CoV-2, Severe Acute Respiratory Syndrome Coronavirus 2; SR, serine/arginine-rich.

https://doi.org/10.1371/journal.pbio.3001425.g001 


\section{Results}

\section{The $\mathbf{N}$ protein phase separates with RNA}

We first asked whether the $\mathrm{N}$ protein forms bimolecular condensates in the presence or absence of viral RNA in vitro. To address this, we expressed wild-type (WT) N protein in HEK293 cells and purified it in a high salt buffer $(1 \mathrm{M} \mathrm{NaCl})$ to eliminate the retention of RNA from human cells [38] (S1A and S1B Fig). Consistent with recent studies, purified N protein eluted from gel filtration as an oligomer in $300 \mathrm{mM} \mathrm{NaCl}$ [26] and had a high affinity for binding to viral and nonviral RNA substrates $[39,40]$ (S1C-S1F Fig). The protein was labeled with a fluorescent dye (LD655) at the carboxyl-terminal ybbR tag and introduced to a flow chamber in the presence or absence of RNA. Phase separation was monitored by the settling of $\mathrm{N}$ or N-RNA condensates onto the coverslip within 25 minutes under highly inclined and laminated optical sheet (HiLO) excitation (see Methods for details). In the absence of RNA, N protein did not form condensates in physiological salt (150 mM NaCl) (Fig 1C). Similarly, 2-kb long polyC RNA homopolymer did not form any condensates in the absence of $\mathrm{N}$ protein (S2A and S2B Fig). Mixing of $50 \mathrm{ng} / \mu \mathrm{L}$ polyC RNA and the $\mathrm{N}$ protein resulted in the formation of condensates in $150 \mathrm{mM} \mathrm{NaCl}$ (Fig 1C). LD655-N and Cy3-polyC colocalized in the droplets, suggesting that phase separation of $\mathrm{N}$ protein is mediated by RNA ( $22 \mathrm{C} \mathrm{Fig).} \mathrm{The} \mathrm{analysis} \mathrm{of}$ the condensates settled on the coverslip revealed a saturation concentration $\left(\mathrm{c}_{\text {sat }}\right)$ of $3.3 \pm 1.3 \mu \mathrm{M}$ for $\mathrm{N}$ protein in the presence of $50 \mathrm{ng} / \mu \mathrm{L}$ polyC RNA ( $\pm \mathrm{SE}$, Fig $1 \mathrm{C}$ ), lower than the concentration of $\mathrm{N}$ protein in infected cells [41]. The partition coefficient of $\mathrm{N}$ protein into condensates was $13 \pm 2( \pm S D)$.

Although $\mathrm{N}$ protein is unable to phase separate in the absence of RNA in $150 \mathrm{mM}$ salt, $24 \mu \mathrm{M} N$ protein efficiently formed condensates without RNA at lower salt with a half-maximal inhibition constant ( $\mathrm{IC}_{50}$ ) of $90 \pm 1 \mu \mathrm{M} \mathrm{NaCl}$ ( \pm SE) (Fig 1D). The addition of $50 \mathrm{ng} / \mu \mathrm{L}$ polyC RNA increased $\mathrm{IC}_{50}$ to $152 \pm 6 \mathrm{mM} \mathrm{NaCl}$ (Fig 1D). The ability of $\mathrm{N}$ protein to phase separate without RNA and sensitivity of these condensates to salt indicates that these condensates may be driven, in part, by electrostatic interactions among $\mathrm{N}$ proteins, as observed for other phase separating systems [42-45].

Condensate formation of $\mathrm{N}$ protein and RNA was dependent on protein-RNA stoichiometry. At $18 \mu \mathrm{M} N$ protein, condensate formation was not observed in the presence of 0 to $5 \mathrm{ng} /$ $\mu \mathrm{L}$ polyC RNA. Increasing the RNA concentration promoted phase separation with an optimal RNA concentration of 100 to $500 \mathrm{ng} / \mu \mathrm{L}$, at which charge neutralization occurs with the positively charged N protein [46]. A further increase in RNA concentration dissolved these condensates (Fig 1E) [47,48]. This reentrant behavior is characteristic of heterotypic RNA and protein interactions in phase separating systems [47].

We also showed that $\mathrm{N}$-polyC condensates exhibit liquid-like, rather than solid-like, material properties. First, these condensates were nearly spherical with an aspect ratio of $1.3 \pm 0.6$ (mean $\pm \mathrm{SD}$ ). Second, we observed the fusion of condensates with a mean fusion time of $90 \pm 30$ seconds (mean \pm SD) after they come into contact (Fig 1F). Finally, fluorescence recovery after photobleaching (FRAP) experiments showed that $90 \pm 10 \%$ of $\mathrm{N}$ protein in condensates can slowly exchange with the solvent with the half recovery time of $80 \pm 30$ seconds (mean $\pm \mathrm{SD}$ ). In comparison, polyC RNA exhibited slower recovery and a lower mobile fraction (Fig $1 \mathrm{G}$ and 1H, S3 Fig), indicating that the RNA may be stabilized by a network of interactions with multiple $\mathrm{N}$ proteins in the condensates.

Similar to polyC RNA, polyA and polyU RNA substrates produced spherical condensates at micromolar concentrations of the N protein (Fig 2A) [49]. However, combining N protein with polyG that forms Hoogsteen base pairing [50] or polyAU that forms Watson-Crick base pair interactions [51] led to the formation of nonspherical condensates (Fig 2A). These results 
A
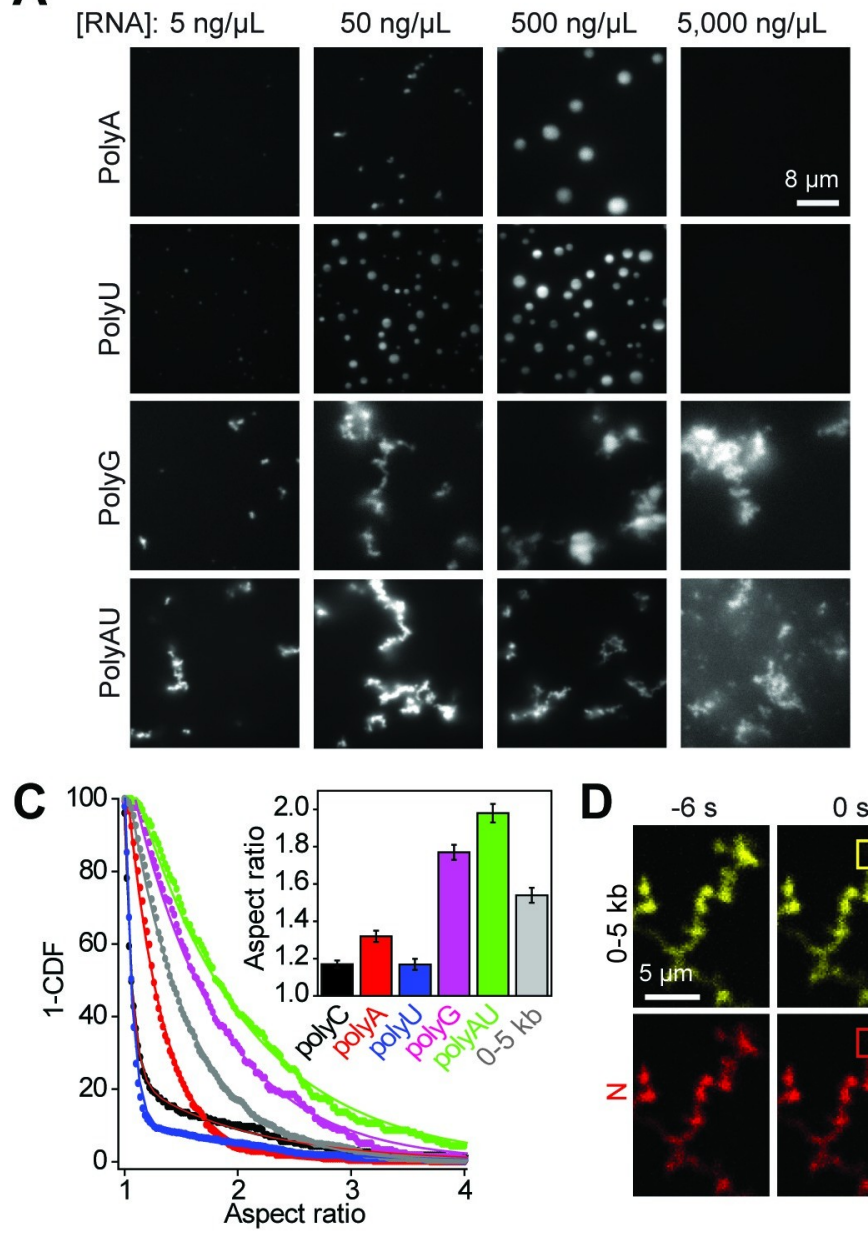

B

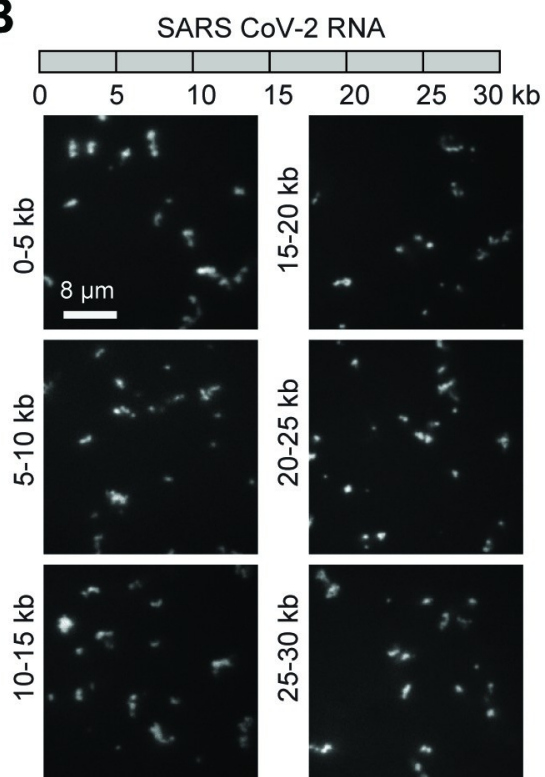

Fig 2. The $\mathrm{N}$ protein forms asymmetric condensates with viral RNA. (A) The $N$ protein forms spherical condensates with polyA and polyU RNA but forms asymmetric condensates with substrates that form Hoogsteen (polyG) and Watson-Crick (polyAU) base pairing interactions. The N protein concentration was set to $18.5 \mu \mathrm{M}$. (B) (Top) SARS-CoV-2 genomic RNA was divided into six 5 -kb sections. (Bottom) The formation of asymmetric $\mathrm{N}$ condensates in the presence of $18 \mathrm{nM}$ RNA. The $\mathrm{N}$ protein concentration was set to $18.5 \mu \mathrm{M}$. (C) The inverse cumulative distribution (1-CDF) of the aspect ratio of individual $\mathrm{N}$ condensates formed with different RNA substrates. The concentrations of N protein, RNA homopolymers, and 0-5 kb viral RNA were set to $18.5 \mu \mathrm{M}, 50 \mathrm{ng} /$ $\mu \mathrm{L}$, and $18 \mathrm{nM}$, respectively. Solid curves represent a fit to exponential decay. (Insert) Decay constants of the exponential fits ( \pm SE). (D) (Left) Representative FRAP imaging of an $\mathrm{N}$ and 0-5 kb viral RNA condensate. The image of a condensate before the time of photobleaching ( 0 second) shows colocalization of Cy3-labeled 0-5 kb viral RNA and LD655-N in the condensate. Rectangles show the photobleached area. (Right) N and 0-5 kb viral RNA do not exhibit fluorescence recovery in the bleached region $(n=16)$. Data underlying this figure can be found in S1 Data. CDF, cumulative distribution function; N, nucleocapsid; SARS-CoV-2, Severe Acute Respiratory Syndrome Coronavirus 2.

https://doi.org/10.1371/journal.pbio.3001425.g002

indicate that the $\mathrm{N}$ protein forms liquid condensates with some of the homopolymeric RNA substrates, whereas other homopolymeric RNA substrates that form base pairing interactions result in asymmetric condensates [19,52-54].

Next, we sought to characterize how the $\mathrm{N}$ protein interacts with SARS-CoV-2 genomic RNA. The SARS-CoV-2 RNA genome was reverse transcribed and assembled into a DNA plasmid [55]. Using this plasmid, we generated six 5-kb fragments (Fig 2B) and two 1-kb fragments of the viral RNA genome via in vitro transcription [56]. In silico methods predict that these RNA fragments can form intra- and intermolecular base pairing interactions and contain extensive secondary structure elements (S4 Fig) $[52,57,58]$. The N protein formed nonspherical condensates with viral RNA fragments across a wide range of protein and viral RNA 
concentrations (Fig 2B and 2C, S4B-S4D Fig). These condensates were dissolved by increasing the salt concentration, but they neither changed shape over time, fused with each other, nor were strongly affected by raising the temperature from $20^{\circ} \mathrm{C}$ to $37^{\circ} \mathrm{C}$ (S5 Fig). We also did not detect fluorescence recovery of either the LD655-labeled $\mathrm{N}$ protein or Cy3-labeled viral RNA in FRAP assays (Fig 2D, S6 Fig). We concluded that N protein forms solid-like condensates with viral RNA in vitro and that base pairing interactions of the RNA may influence the material properties of the condensate $[19,52,53]$.

\section{CLMS identifies $\mathbf{N}$ protein interaction sites}

To understand the mechanism of phase separation of the $\mathrm{N}$ protein, we performed CLMS to identify interactions between different domains of the full-length $\mathrm{N}$ protein in the absence of RNA [59]. CLMS detects protein-protein contacts by covalently capturing closely positioned lysine residues with bifunctional reagents. We first cross-linked the soluble (not phase separated) $\mathrm{N}$ protein in $300 \mathrm{mM} \mathrm{KAc}$ using a bifunctional cross-linker bis(sulfosuccinimidyl) suberate (BS3) (S7A Fig) [38]. We detected that the N-terminal half of the protein, including NTD, makes diverse contacts throughout the entire protein (S7A Fig). There was also an abundance of contacts between the regions immediately flanking the CTD on either side, referred to as R1 (amino acids 235 to 256) and R2 (amino acids 369 to 390).

Next, we performed quantitative CLMS measurements [60] comparing the soluble $\mathrm{N}$ protein in $300 \mathrm{mM} \mathrm{KAc}$ with phase-separated N protein in $100 \mathrm{mM} \mathrm{KAc}$ (Fig 3A). The soluble $\mathrm{N}$ protein was cross-linked with heavy (D12) BS3, whereas the phase-separated protein was cross-linked with light (H12) BS3. As a result, the cross-linked precursor ions from high and low salt conditions were spaced by $12 \mathrm{Da}$ (Fig $3 \mathrm{~A}$ ). Interactions between specific regions that promote condensate formation are implicated by the ratio of the cross-linked precursor ion signal and its corresponding isotopic doublet (Fig 3A) [60]. This experiment was repeated by reversing the labels, such that (H12) BS3 was used to cross-link the soluble N protein and (D12) BS3 was used for the phase-separated N protein. Across 2 independent experiments, 29 unique cross-links were enriched, and 30 cross-links were depleted upon phase separation (Fig 3B-3C, S7B Fig). Although lysine residues are distributed throughout the N protein (S7A Fig) and depleted cross-links spanned the entire primary sequence, the analysis of the cross-link fold change (S1 Table) revealed that nearly all of the enriched interactions are concentrated in regions $\mathrm{R} 1$ and $\mathrm{R} 2$ (Fig $3 \mathrm{C}$ ). These results suggest that the interactions involving the amino acids in regions R1 and R2 may be important in driving phase separation (Fig 3D, S7C Fig).

Our mass spectrometry (MS) analysis also found phosphorylation sites on the N protein (Fig $3 \mathrm{E})$. While some of these sites have been identified in previous studies [10,61,62], we also identified several novel sites (S2 Table). Although one of the phosphorylation sites (S176) is involved in a cross-link, the phosphorylated and unphosphorylated peptides were both strongly depleted in condensates, suggesting that S176 phosphorylation does not play a major role in phase separation (S1 and S2 Tables, S7B Fig). Additionally, MS identified native proteins that co-purified with the $\mathrm{N}$ protein in $1 \mathrm{M}$ salt (S3 Table). Consistent with the recruitment of $\mathrm{N}$ to stress granules in cells $[1,13,46,63], 2$ of the most frequently identified proteins were stress granule proteins G3BP1 and G3BP2, with R2 of the N protein interacting with G3BP1 (S7D Fig).

\section{The carboxyl-terminal region and phosphorylation modulate phase separation}

The quantitative CLMS experiments show that interactions between R1 and R2 are correlated with the formation of condensates. However, we could not exclude the possibility that some of the changes in pairwise interactions are due to differences in protein structure or electrostatic 
A

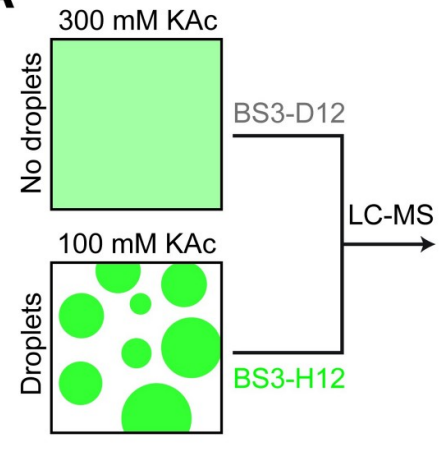

B
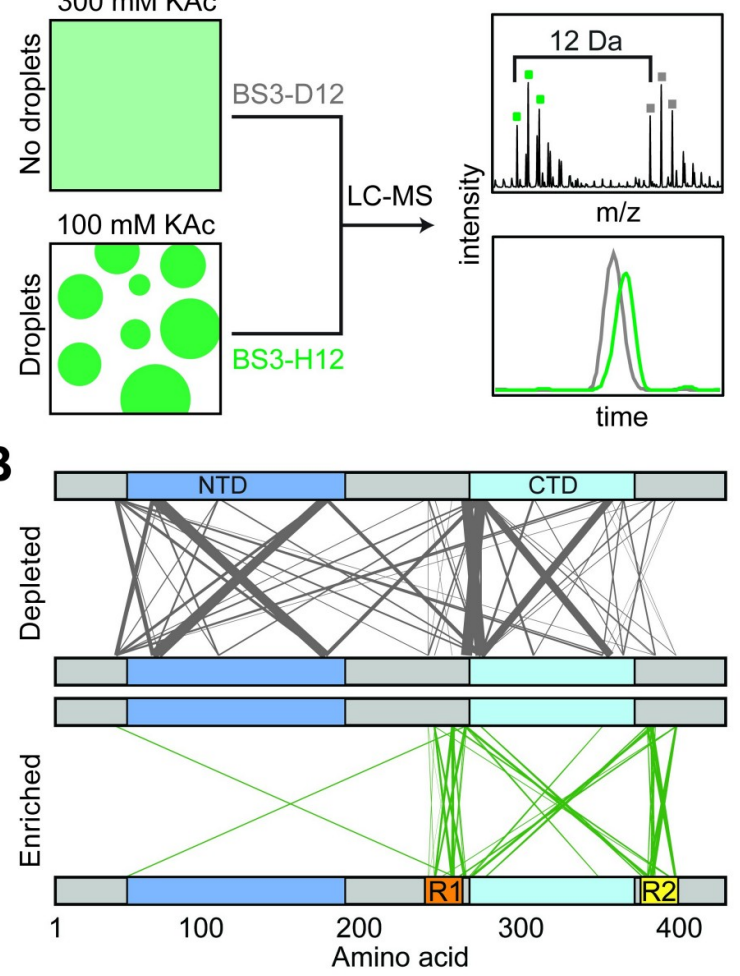

C

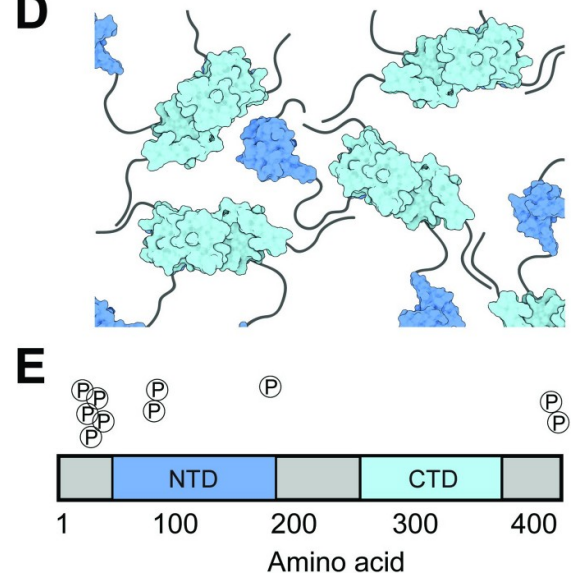

Fig 3. CLMS reveals interdomain interactions of the $\mathrm{N}$ protein. (A) Schematic of the CLMS experiment. (Left) A high salt (300 mM KAc) buffer disrupts $\mathrm{N}$ condensates, whereas a low salt (100 mM KAc) buffer promotes condensate formation. (Right, top) Example of an individual cross-linked peptide in quantitative CLMS analysis. Precursor ions from the high salt (gray) and low salt (green) BS3 cross-linking conditions show the $12 \mathrm{Da}$ shift between light (H12) and heavy (D12) cross-linkers. (Right, bottom) Ion chromatograms from the first 3 isotopes of each doublet were extracted and expressed as the ratio of peak areas. (B) The plot of cross-links depleted and enriched in the condensate condition. The width and transparency of the lines scale with the number of times the cross-link were detected across 3 independent experiments. (C) Fold changes of cross-link abundance upon condensate formation of N. As cross-links contain 2 positions, fold change information is plotted at both positions. Only cross-links with $p$-values less than 0.05 are included. Green and gray dots represent cross-links enriched and depleted in the condensate condition, respectively. The blue area represents a plot of median cross-link fold change. Data underlying this figure can be found in S1 Table. (D) Model for how multiple $\mathrm{N}$ dimers could phase separate via their disordered regions. (E) Phosphorylation sites detected by the CLMS experiment in $300 \mathrm{mM}$ KAc. CLMS, cross-linking mass spectrometry; CTD, carboxyl-terminal domain; N, nucleocapsid; NTD, N-terminal domain.

https://doi.org/10.1371/journal.pbio.3001425.g003

interactions induced by differences in salt concentrations used for the soluble and condensate phase. To directly test the predictions of the CLMS results, we determined how different domain deletions affected phase separation of the $\mathrm{N}$ protein with polyC RNA under the same salt concentration (Fig 4A, S8A Fig). The $\Delta \mathrm{SR}, \Delta \mathrm{PLD}$, and $\Delta \mathrm{R} 1$ mutants formed spherical condensates with polyC RNA (Fig 4B, S9 Fig), suggesting that these regions are not essential for phase separation. In comparison, deletion of the $\mathrm{R} 2$ sequence fully abolished the formation of condensates with polyC RNA (Fig 4B, S9A-S9D Fig). Similarly, $\Delta$ R2 was unable to form condensates with viral RNA, whereas other deletion mutants phase separated with the same RNA fragments (S9E Fig). $\triangle \mathrm{R} 2$ maintained a high affinity to bind polyC and viral RNA (S8C Fig), excluding the possibility that the disruption of phase separation is due to the lack of proteinRNA interactions. These results show that protein-protein interactions driven by the $\mathrm{R} 2$ motif are required for phase separation of $\mathrm{N}$ protein with RNA, consistent with the proposed role of this sequence in the oligomerization of $\mathrm{N}$ protein [26]. 


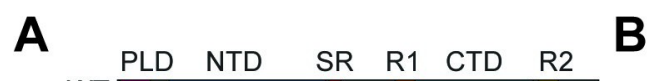

B
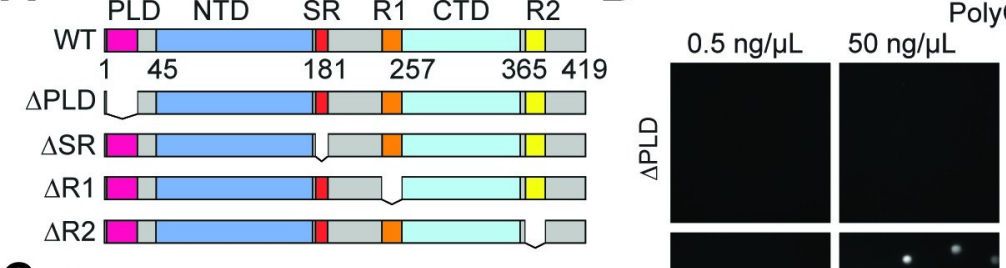

PolyC
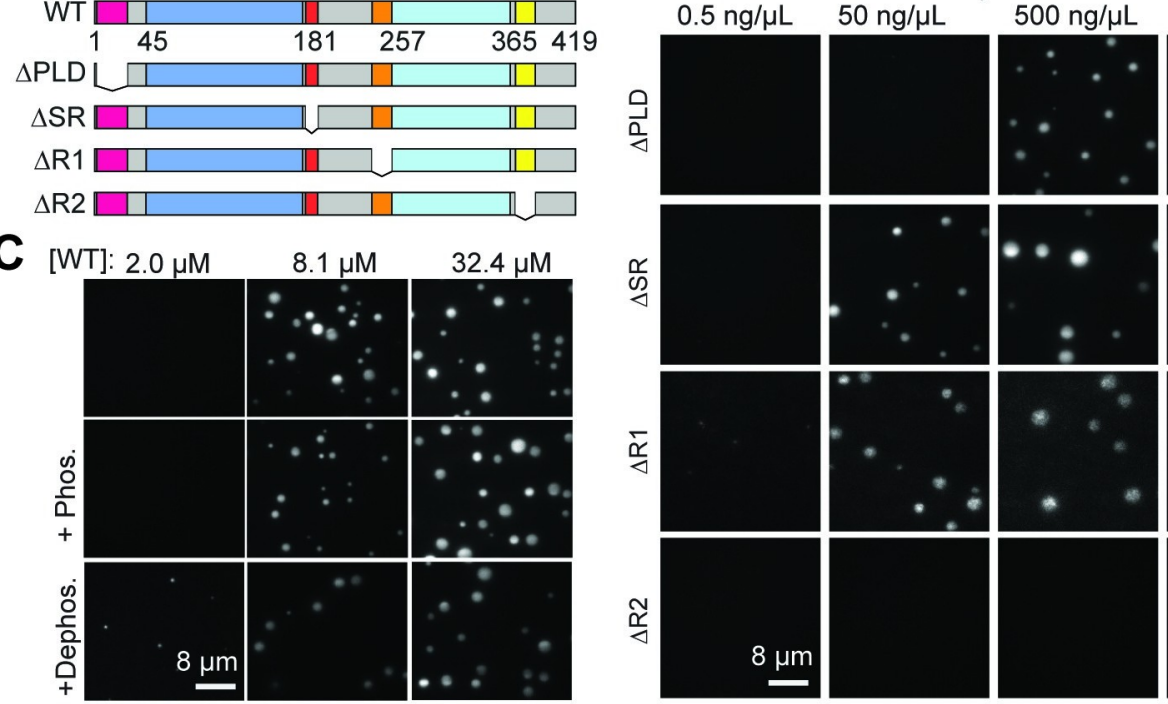

$5 \mu g / \mu L$
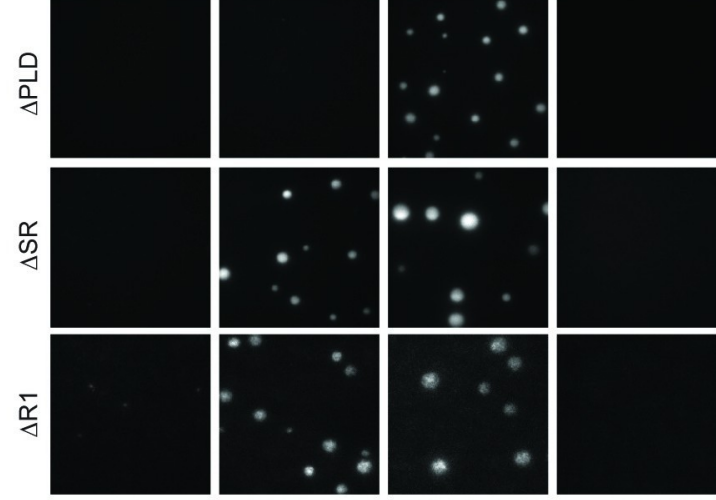

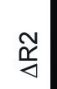
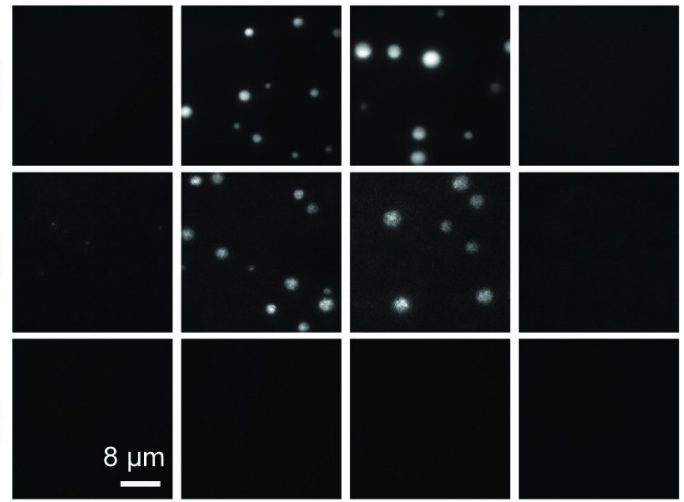

D

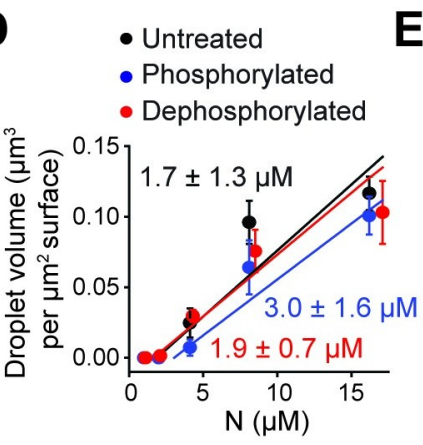

$E$
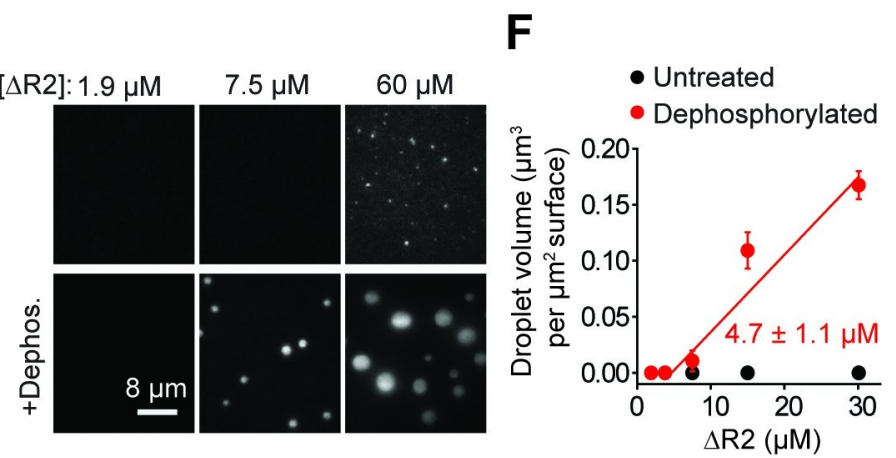

Fig 4. The effect of domain deletions and phosphorylation on phase separation of the $\mathrm{N}$ protein. (A) Deletion mutants of the $N$ protein. (B) While $\Delta P L D, \Delta S R$, and $\Delta R 1$ phase separate, $\Delta R 2$ does not phase separate when mixed with polyC RNA. Protein concentration was set at $18 \mu \mathrm{M}$ for all conditions. (C) Images of condensates formed by untreated, phosphorylated, and dephosphorylated $\mathrm{N}$ protein in $50 \mathrm{ng} / \mu \mathrm{L}$ polyC RNA. (D) The total volume of N-RNA condensates settled per micron squared area on the coverslip under different phosphorylation conditions (mean $\pm \mathrm{SD}, n=20$ with 2 technical replicates). Linear fits (solid lines) reveal $\mathrm{c}_{\mathrm{sat}}( \pm \mathrm{SE})$. (E) Images of condensates formed by untreated and dephosphorylated $\Delta \mathrm{R} 2$ in $50 \mathrm{ng} / \mu \mathrm{L}$ polyC RNA. (F) The total volume of $\Delta \mathrm{R} 2$-RNA condensates settled per micron squared area on the coverslip as a function of $\Delta \mathrm{R} 2$ concentration (mean $\pm \mathrm{SD}, n=20$ with 2 technical replicates). The linear fit (solid line) reveals $\mathrm{c}_{\mathrm{sat}}( \pm \mathrm{SE})$. Data underlying this figure can be found in S1 Data. CTD, carboxyl-terminal domain; N, nucleocapsid; NTD, N-terminal domain; PLD, prion-like domain; SR, serine/arginine-rich; WT, wild-type.

\section{https://doi.org/10.1371/journal.pbio.3001425.g004}

Recent studies proposed that the $\mathrm{N}$ protein is phosphorylated early in infection, and this results in localization of N protein with the RTC, where it enhances transcription of subgenomic RNA [64]. However, nucleocapsid formation does not require phosphorylation and $\mathrm{N}$ protein in SARS-CoV viruses is hypophosphorylated $[64,65]$. The underlying molecular mechanism and kinases and phosphatases responsible for posttranslational modification of N protein remain poorly understood [8]. To understand how phosphorylation affects phase separation, we treated the full-length $\mathrm{N}$ protein with casein kinase 2 and $\lambda$ protein phosphatase (see Methods). While kinase treatment did not alter the migration of $\mathrm{N}$ protein on a denaturing gel, phosphatase treatment resulted in a reduction in molecular weight (S8A Fig), suggesting that the $\mathrm{N}$ protein expressed in human cells is phosphorylated. Phosphatase treatment resulted in phase separation at slightly lower concentrations in comparison to kinase-treated 
$\mathrm{N}$ protein (Fig 4C and 4D). Similar to WT N, dephosphorylated $\Delta$ SR or $\Delta \mathrm{R} 1$ had only a moderate increase in phase separation (S8 and S10 Figs). However, unlike untreated $\Delta \mathrm{R} 2$, dephosphorylated $\Delta \mathrm{R} 2$ exhibited robust phase separation with polyC RNA (Fig $4 \mathrm{E}$ and $4 \mathrm{~F}$ ). These results suggest that phosphorylated $\mathrm{N}$ is capable of phase separation with RNA, primarily due to interactions between R2 motifs. In the absence of the R2 motif, phosphorylation negatively regulates phase separation of the $\mathrm{N}$ protein.

\section{Targeting phase separation of the $\mathrm{N}$ protein with small molecules}

We next sought to identify small molecules that could interfere with the phase separation of the $\mathrm{N}$ protein. The condensates formed by the $\mathrm{N}$ protein in the absence or presence of polyC or viral RNA dissolve with the addition of 10\% 1,6 hexanediol, indicating that phase separation is driven, at least partially, by hydrophobic interactions (Fig 5A) [45]. In comparison, lipoic acid that increases the liquidity of stress granules [66] did not affect phase separation (Fig 5A). Using a high-throughput microscopy platform, we also tested whether any of the 1,200 compounds in a Food and Drug Administration (FDA)-approved drug library alters phase separation of the $\mathrm{N}$ protein with polyC RNA in vitro. While none of the compounds fully dissolved the condensates, we identified several compounds that affected their number, size, and shape (S4 Table). Nelfinavir mesylate and LDK378 produced larger but fewer condensates, whereas crystal violet, tolcapone, and chlorhexidine enhanced phase separation by increasing the number and size of the condensates (Fig 5B, S11A and S11B Fig). Nilotinib resulted in a 50\% increase in condensate volume and altered the shape of the condensates (Fig 5B), which may be due to changes in condensate fusion or maturation. While most drugs did not have a substantial effect on condensates formed by $\mathrm{N}$ and viral genomic RNA in vitro, nilotinib addition resulted in the formation of thread-like filaments (S11C and S11D Fig). Morphologically, these filaments were similar to those formed during the liquid-to-solid transition of FUS condensates [67], suggesting that nilotinib increases the viscosity of the condensates.

We then tested these drugs in human pulmonary epithelial (Calu-3) and African Green Monkey kidney (Vero-E6) cells infected with SARS-CoV-2 (see Methods), as these cell lines supported high levels of infection [68]. The cells were treated with different concentrations of drugs 1 hour before infection, and the inhibition of SARS-CoV-2-mediated cell death under drug treatment was quantified using the cytopathic effect (CPE) inhibition assay [68]. The toxicity of the drugs was quantified by measuring the viability of uninfected cells under drug treatment. Among the molecules we identified, nelfinavir mesylate resulted in the highest percent CPE inhibition in both cell lines without significantly affecting cell viability (Fig 5C, S12A Fig), with the exception that the highest dose $(40 \mu \mathrm{M})$ was toxic to the cells.

We also tested the effectiveness of these drugs using a median tissue culture infectious dose $\left(\mathrm{TCID}_{50}\right)$ assay. The supernatant from Vero-E6 cells that had been cultured with virus and drugs was added to uninfected cells, and the viral titer was measured by observing CPE in these cells. In this assay, nelfinavir mesylate, nilotinib, and LDK378 each reduced SARS-CoV2 titer viability, with nilotinib and LDK378 producing an inhibitory effect similar to remdesivir, which strongly inhibits proliferation of SARS-CoV-2 in infected cells (Fig 5C, S12B Fig) [69]. Collectively, our drug screen identified compounds that affect the condensate formation of N protein and RNA in vitro, inhibit virus-mediated cell death, and reduce viral titer.

\section{The $\mathrm{N}$ protein phase separates in mammalian cells}

To test whether $\mathrm{N}$ protein also phase separates in mammalian cells, we expressed N-GFP in HEK293T cells. We observed the formation of distinct puncta in the cytoplasm of N-GFPexpressing cells, which were not observed in control cells expressing GFP only (Fig 6A). FRAP 
A

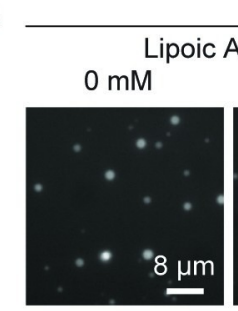

B
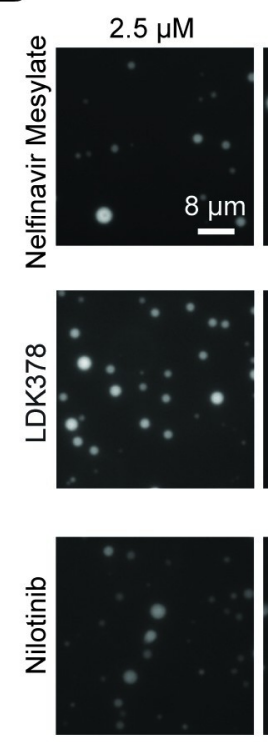

polyC

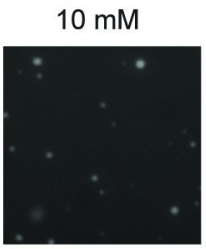

$40 \mu \mathrm{M}$
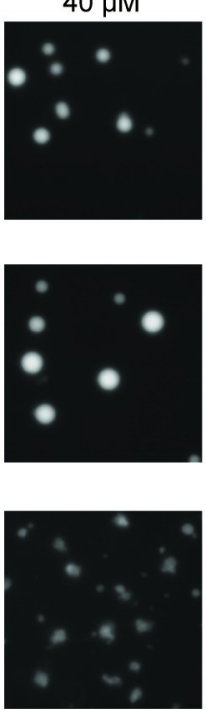

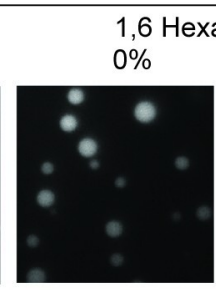

1,6
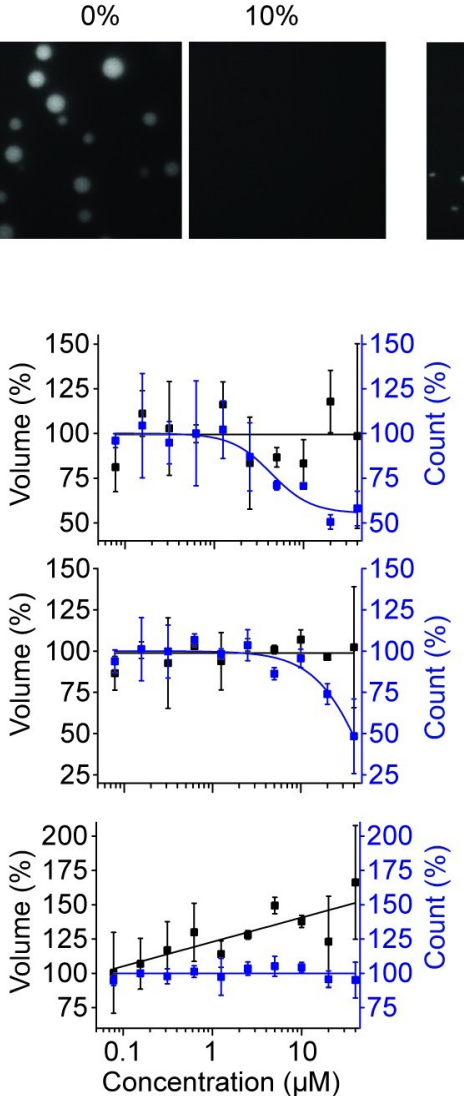

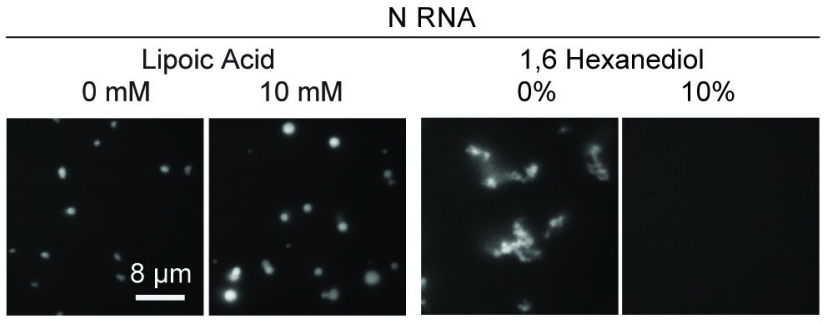

C
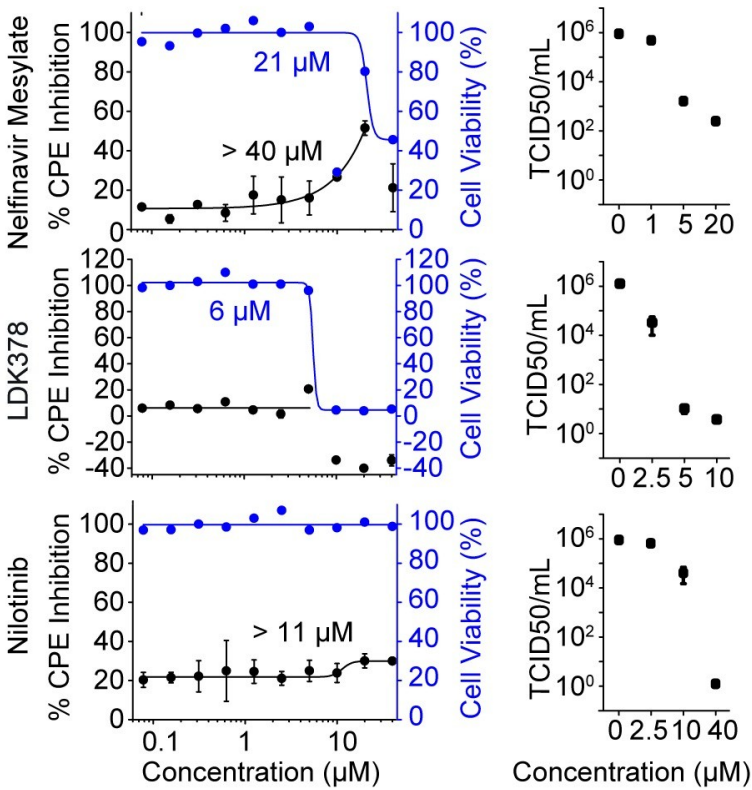

Fig 5. Identification of small molecules that alter phase separation of $\mathrm{N}$ in vitro and reduce viral titer in SARS-CoV-2 infected cells. (A) Condensates

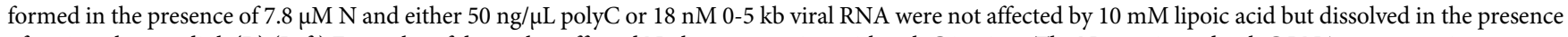
of 10\% 1,6 hexanediol. (B) (Left) Examples of drugs that affected $\mathrm{N}$ phase separation with polyC in vitro. The $\mathrm{N}$ protein and polyC RNA concentrations were set to $7.8 \mu \mathrm{M}$ and $50 \mathrm{ng} / \mu \mathrm{L}$, respectively. (Right) The percent change on the number (blue) and total volume (black) of N-polyC condensates settled per micron squared area on the coverslip under different drug concentrations (mean $\pm \mathrm{SD}, n=8$ with 2 technical replicates). Solid curves represent a fit to a dose-response equation (see Methods). (C) (Left) Percent CPE inhibition (black, mean \pm SD, 2 technical replicates) and cell viability (blue) of SARS-CoV-2-infected Vero-E6 cells treated with serial dilutions of drugs. Solid curves represent a fit to a dose-response equation (see Methods) to determine a half-maximal response constant $\mathrm{EC}_{50}$ (S4 Table). (Right) Viral titer in SARS-CoV-2-infected Vero-E6 cells treated with serial dilutions of drugs as measured by a TCID 50 assay (mean \pm SD, 3 technical replicates). Data underlying this figure can be found in S1 Data. CPE, cytopathic effect; N, nucleocapsid; SARS-CoV-2, Severe Acute Respiratory Syndrome Coronavirus 2; TCID, tissue culture infectious dose.

https://doi.org/10.1371/journal.pbio.3001425.g005

imaging of these puncta revealed a recovery signal with $60 \%$ mobile fraction and $6.3 \pm 0.1 \mathrm{sec}-$ onds recovery lifetime, suggesting that $\mathrm{N}$ protein is capable of forming liquid condensates in cells (Fig 6B, S13A-S13D Fig). The recovery of N-GFP was substantially slower than GFP only (Fig 6C-6E), but an order of magnitude faster than that of $\mathrm{N}$-polyC condensates in vitro (Fig $1 \mathrm{H})[8,38]$, suggesting that these condensates are less viscous than $\mathrm{N}$-polyC condensates formed in vitro. This difference is not due to the absence or low stoichiometry of RNA in $\mathrm{N}$-GFP puncta in live cells because $\mathrm{N}$ condensates formed in the absence of RNA in vitro also exhibited an order of magnitude slower recovery than N-GFP puncta in live cells (S14 Fig). We next tested whether deletion of the $\mathrm{R} 2$ region disrupts phase separation of $\mathrm{N}$ protein in cells. Surprisingly, cells expressing the R2 deletion mutant ( $\triangle \mathrm{R} 2-\mathrm{GFP})$ still formed puncta and did not display significantly different FRAP recovery times than N-GFP in live cells (Fig 6A$6 \mathrm{E})$. This may be due to macromolecular crowding of the cellular environment because the 
A

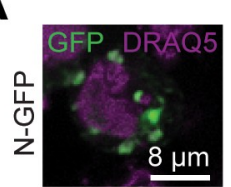

B
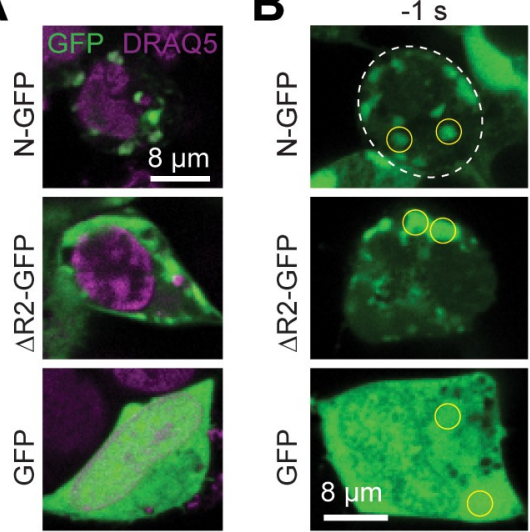

C

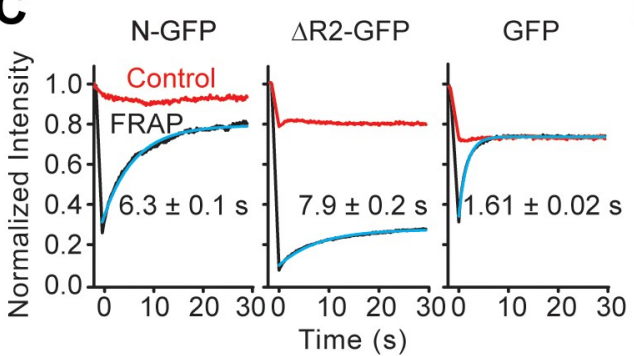

$\mathbf{F}$
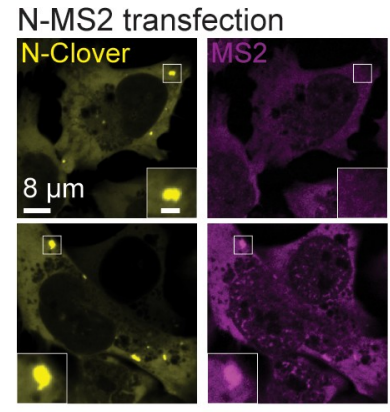

G
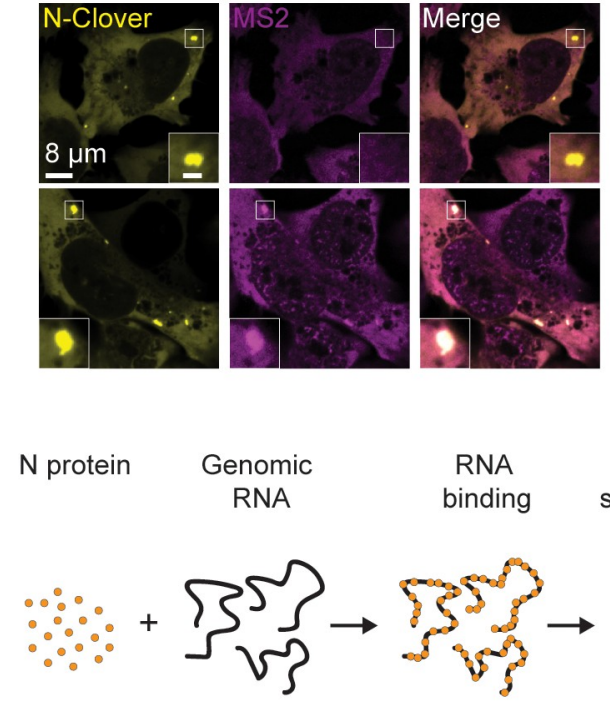

$0 \mathrm{~s}$
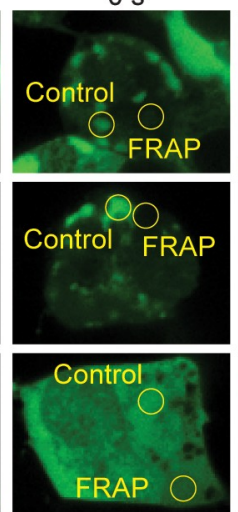

D
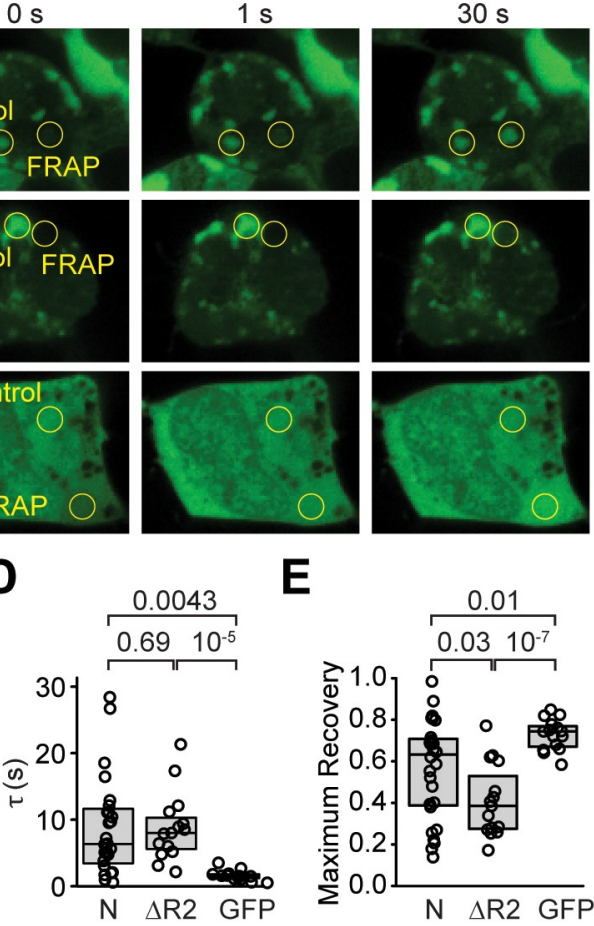

E

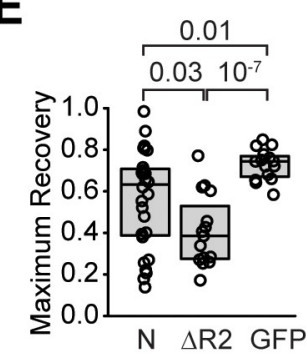

No transfection
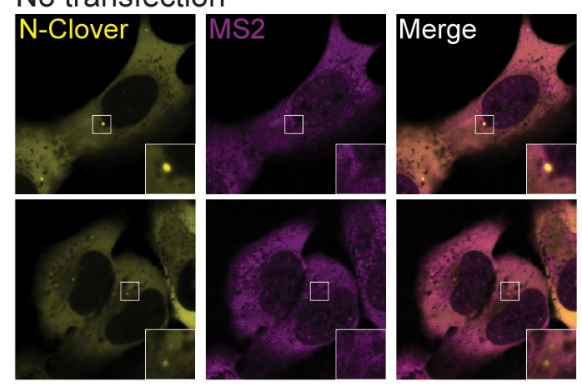

Phase separation
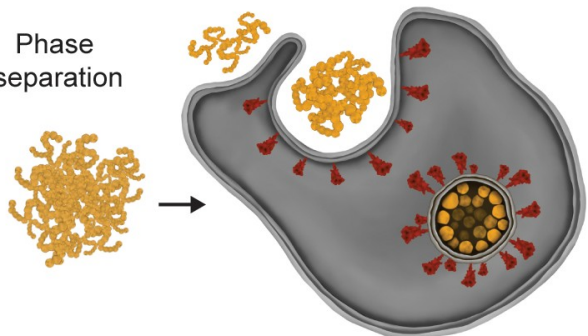

Fig 6. Dynamics of $\mathbf{N}$ condensates in vivo. (A) Example images of HEK293T cells expressing N-GFP, $\Delta R 2-G F P$, and GFP stained with DRAQ5. (B) Representative FRAP imaging of cells exhibiting N-GFP or $\triangle$ R2-GFP puncta or high GFP expression. Circles show the photobleached area. (C) Fluorescence recovery of the GFP signal in the bleached versus the control regions. The solid curve represents a single exponential fit to reveal the recovery lifetime ( $\tau, \pm 95 \%$ confidence interval). (D) The distribution of fluorescence recovery lifetimes of cells expressing N-GFP $(n=28)$ or $\triangle$ R2-GFP $(n=15)$ exhibiting puncta and GFP only $(n=15)$. The center and edges of the box represent the median with the first and third quartiles. The $p$-values were calculated from a 2 -tailed $t$ test. (E) The maximum fractional recovery after photobleaching of cells expressing N-GFP $(n=28), \Delta$ R2-GFP $(n=15)$, or GFP only $(n=15)$. The center and edges of the box represent the median with the first and third quartiles. The $p$-values were calculated from a 2 -tailed $t$ test. (F) U2OS cells stably expressing N-Clover form condensates in the cytoplasm. (Left) Cells co-transfected with an N-MS2 expression plasmid exhibit colocalization of N-Clover and Cy3-MS2 FISH signal in N-condensates ( $N=10$ out of 55 cells, 2 technical replicates). (Right) The Cy3-MS2 FISH probe does not partition into $\mathrm{N}$ condensates 
in untransfected cells ( $N=55$ cells, 2 technical replicates). Inset scale bar is $2 \mu \mathrm{m}$. (G) Model for remodeling of viral RNA genome by the SARS-CoV-2 N protein. The $\mathrm{N}$ protein packages viral genomic RNA through phase separation, which may facilitate efficient replication of the genomic RNA and the formation of the enveloped virus. Data underlying this figure can be found in S1 Data. FRAP, fluorescence recovery after photobleaching; N, nucleocapsid; SARS-CoV-2, Severe Acute Respiratory Syndrome Coronavirus 2.

https://doi.org/10.1371/journal.pbio.3001425.g006

addition of $10 \%$ polyethylene glycol (PEG) triggered phase separation of $\Delta \mathrm{R} 2$ in vitro (S15 Fig).

Additionally, we sought to determine whether the N RNA transcript was recruited to the $\mathrm{N}$ condensate. We transfected U2OS cells stably expressing N-Clover [38] with a construct producing N-MS2 RNA (see Methods) and performed fluorescence in situ hybridization (FISH) assays against the MS2 RNA sequence. In the absence of N-MS2 transfection, the MS2 probe did not localize to the $\mathrm{N}$-Clover puncta in any of the cells ( $N=55$ cells, 2 independent experiments) (Fig 6F). In comparison, the MS2 probe was strongly localized to all of the $\mathrm{N}$-Clover condensates in approximately $18 \%$ of the cells transfected with N-MS2 ( $N=10$ in 55 cells, 2 independent experiments, Fig 6F). In other cells, we observed that the MS2 probe was uniformly distributed inside and outside of the $\mathrm{N}$ puncta, suggesting that these cells were not expressing N-MS2 at high enough levels to recruit the probe. We also performed RNA FISH using a $\mathrm{d}(\mathrm{T}) 20$ probe that binds the polyA tails of RNA transcripts. Consistent with a previous report [38], the $\mathrm{d}(\mathrm{T}) 20$ probe was not recruited to N-Clover condensates (S13E Fig). These results suggest that N-Clover condensates selectively recruit viral RNA. Differences between in vitro and in vivo phase separation properties of $\mathrm{N}$ protein might be attributed to macromolecular crowding of the cytosol or the interaction of the $\mathrm{N}$ protein with other cellular proteins, such as G3BP1 (S7D Fig) $[1,46,63,70]$.

\section{Discussion}

In this study, we showed that the SARS-CoV-2 $\mathrm{N}$ protein phase separates with viral and nonviral RNA sequences in vitro and the viscosity and shape of these condensates depend on the structure of the RNA substrate. Concurrent studies have shown that the SARS-CoV-2 N protein expressed in bacteria forms biomolecular condensates with RNA in vitro $[8,31,36,38,46,54,56,63,71-74]$. We purified $\mathrm{N}$ protein from mammalian cells to recapitulate the posttranslational modifications that occur in infected human cells [10]. Consistent with previous reports, we observed that the $\mathrm{N}$ protein forms liquid condensates with various RNA substrates in physiological salt $[8,36]$. Condensates of $\mathrm{N}$ with homopolymeric RNA that do not form Watson-Crick or Hoogsteen base pairing interactions recovered from photobleaching and relaxed to a spherical shape, suggesting that they are dynamic, liquid-like compartments. In agreement with Iserman and colleagues, we found that RNA structure affects the material properties of the condensate [56]; RNA capable of Watson-Crick or Hoogsteen base pairing produces irregularly shaped condensates [54,73]. N protein also formed solid-like condensates with long fragments of SARS-CoV-2 genomic RNA. These condensates had asymmetric shapes and did not relax over time or with increased temperature $[8,46]$. Viral RNA may drive the formation of abnormal condensate shapes by forming networks of intermolecular interactions, as previously reported $[19,52,53,75]$.

We also investigated the mechanisms underlying condensate formation using CLMS and protein engineering [38]. Previous studies reported that prion-like and SR motifs are common features of phase separating proteins [29,33], and the linker sequence outside the SR motif (amino acids 210 to 247) is essential for phase separation of $\mathrm{N}$ expressed in bacteria [38]. The $\mathrm{SR}$ motif was required for N/N interactions in SARS-CoV and for forming puncta in 
SARS-CoV-infected cells [76]. In addition, the SR motif is highly phosphorylated in human cells, and phosphorylation has been shown to promote interactions with host proteins, nuclear targeting, and transcription of the viral genome and either enhances or inhibits oligomerization in SARS-CoV $[13,64,65,77]$. In SARS-CoV-2, SR phosphorylation is reported to make $\mathrm{N}$ condensates more liquid $[8,38]$, and the deletion of the SR domain enhanced $N$ phase separation in cells $[38,63]$. However, we observed that the SR region is not necessary for in vitro condensate formation of $\mathrm{N}$ protein expressed in human cells. The deletion of the entire carboxylterminal IDR was reported to enhance phase separation $[8,26]$. We found that deletion of the $\mathrm{R} 2$ motif in this region is sufficient to disrupt phase separation of $\mathrm{N}$ protein with both homopolymeric and viral RNA in vitro, but dephosphorylation of this mutant recovered phase separation. The carboxyl-terminal region interacts with the $\mathrm{M}$ protein, which was shown to drive phase separation of the N protein in the absence of RNA [26]. Because this region plays an important role in phase separation, binding to the membrane-associated $\mathrm{M}$ protein through this region can alter the material properties of the N-RNA condensates and initiate virion assembly.

It remains to be demonstrated whether condensate formation of $\mathrm{N}$ protein and the viral genome is essential for the propagation of SARS-CoV-2 in human cells. For example, several viruses have been shown to replicate in viral inclusion bodies that are characterized as phaseseparated condensates $[23,24]$. A recent in vitro work has shown that nucleoproteins and phosphoproteins of the measles virus form liquid-like membraneless organelles and triggered nucleocapsid formation [18], suggesting that phase separation could be a general mechanism for viral replication. In the case of SARS-CoV-2, phase separation of $\mathrm{N}$ protein can form membrane-less compartments and function as a selectivity barrier to control the entry of certain agents into these compartments. Recent in vitro studies have shown that N-RNA condensates recruit the components of the SARS-CoV-2 replication machinery [46]. This mechanism may increase the efficiency of replication of the viral genomic RNA by increasing the local concentration of the replication machinery at the RTC complex.

$\mathrm{N}$ condensates may also sequester the viral assemblies from the immune response of the host cell [8]. For example, N protein interacts with stress granule proteins G3BP1 and G3BP2 in vitro $[1,54,63]$, localizes to stress granules in cells $[1,13,46,63]$, and inhibits stress granule formation in cells overexpressing N protein [70, 78] and in SARS-CoV-2-infected cells [79]. N mutants that do not interact with G3BP1 failed to suppress stress granule formation in SARS-CoV-2-infected cells, and these cells were impaired in mediating SARS-CoV-2 viral-like particle (VLP) production [80]. LLPS of SARS-CoV-2 N protein has also been shown to inhibit poly-ubiquitination and aggregation of mitochondrial antiviral-signaling protein (MAVS, also known as IFN- $\beta$ promoter stimulator I) and thereby suppress the antiviral immune response [79]. Lys375 mutation or a peptide targeting the CTD of N protein disrupted LLPS of $\mathrm{N}$ with RNA in vitro, inhibited SARS-CoV-2 replication, and rescued antiviral immunity in mice [79]. Future work will be required to dissect the precise role of $\mathrm{N}$-mediated phase separation in suppression of the innate immune response in infected organisms.

The phase separation of $\mathrm{N}$ protein with viral RNA may also facilitate the compaction and packaging of the genome into the nascent viral particle (Fig 6G) $[81,82]$. However, this model raises several questions. Because $\mathrm{N}$ protein can phase separate with nonspecific RNA substrates, it remains unclear how these condensates may exclude subgenomic viral RNA and other RNA from the host cell. Recent in vitro work has shown that $\mathrm{N}$ protein has a higher affinity to bind $5^{\prime}$ and $3^{\prime}$ untranslated regions (UTRs) of the genomic RNA [56,71], which may serve as a mechanism to trigger genome packaging and exclude other RNA from the condensates. In addition, condensates observed in vitro and in vivo are large structures that can potentially contain thousands of $\mathrm{N}$ proteins and RNAs, and it is not clear how a virion with a 
single genomic RNA can bud from these structures. A recent modeling study proposed that the presence of high-affinity sites in genomic RNA can trigger the formation of single-genome condensates [31]. Alternatively, interaction with the $\mathrm{M}$ protein or dephosphorylation of $\mathrm{N}$ protein, which could trigger the liquid-to-solid transition of N-RNA condensates [8,38], at the viral assembly sites may trigger budding of a single genomic copy in virions. A condensate formed by $\mathrm{N}$ and a single genomic copy is expected to be stabilized once encapsulated in a lipid bilayer of the virion, and this would allow the virus to maintain its genome organization in a dilute phase. Testing of these models requires in-depth studies of $\mathrm{N}$ protein and genomic RNA in SARS-CoV-2-infected cells.

Phase separation could also provide a macroscopic readout to study N protein and RNA interactions [66] and suggests novel strategies to disrupt genome packaging and viral propagation in infected cells. We performed a screen of an FDA-approved drug library and identified several compounds that altered the size, number, and shape of N/RNA condensates in vitro. In particular, nelfinavir mesylate binds the SARS-CoV-2 protease [83-86], and both nelfinavir mesylate and nilotinib were shown to block SARS-CoV viral production $[87,88]$. We showed that nelfinavir mesylate, nilotinib, and LDK378 each inhibit the proliferation of SARS-CoV-2 in the host cell, which may be related to changes they induce on $\mathrm{N}$ condensates. Future work in infected cells is needed to address whether these drugs reduce virus-mediated cell death by interfering with the functions of N-RNA condensates.

\section{Methods}

\section{Protein purification}

A construct for expressing $\mathrm{N}$ protein with a carboxyl-terminal Strep-tag was obtained from the Krogan lab (UCSF). A carboxyl-terminal yBBr labeling site was added for labeling with a fluorescent dye. Deletion mutants, $\triangle$ PLD (amino acids 2 to 30: SDNGPQNQRNAPRITFGGPS DSTGSNQNG), $\triangle$ SR (amino acids 183 to 195, SSRSSSRSRNSSR), $\Delta R 1$ (amino acids 235 to 256, SGKGQQQQGQTVTKKSAAEASK), and $\triangle$ R2 (amino acids 369 to 390, KKDKKKKADETQALPQRQKKQQ) were generated using Gibson cloning (New England Biosciences, Massachusetts, USA). Sufficient amounts of DNA were obtained by growing $1 \mathrm{~L}$ of transfected XL1 Blue Escherichia coli cells overnight and performing a gigaprep (Zymo, California, USA). For protein expression, HEK293S GNTI- cells (RRID: CVCL_A785) were grown in suspension in Freestyle media (Thermo Fisher Scientific, Massachusetts, USA) supplemented with 2\% fetal bovine serum (FBS, VWR, Pennsylvania, USA) and 1\% penicillin-streptomycin (PS, Gemini Bio Products, California, USA) to 2 million cells $/ \mathrm{mL}$. Cells were spun down for 10 minutes at $1,200 \mathrm{~g}$ and resuspended in fresh, antibiotic-free media. For $250-\mathrm{mL}$ cells, the transfection solution was created by mixing $1.8-\mathrm{mL}$ polyethylenimine $(1 \mathrm{mg} / \mathrm{mL}, \mathrm{pH} 7.0$ in PBS) dissolved in 20-mL Freestyle media and 0.66-mg DNA dissolved in 20-mL Freestyle media. The mixture was incubated at room temperature for 15 minutes before being adding it to the cell culture. Transfected cell culture was grown for 72 hours at $125 \mathrm{rpm}$ at $37^{\circ} \mathrm{C}$ with $5 \% \mathrm{CO}_{2}$ and $5 \%$ humidity.

Cells were then harvested at 4,000 $\mathrm{g}$ for 10 minutes and resuspended in $50 \mathrm{~mL}$ lysis buffer (50 mM HEPES pH 7.4, $1 \mathrm{M} \mathrm{NaCl}, 1 \mathrm{mM}$ PMSF, $1 \mathrm{mM} \mathrm{DTT}$, and 1 tablet of protease inhibitor (Sigma-Aldrich, Missouri, USA)). Lysis was performed using 15 loose and 15 tight plunges of a Wheaton glass dounce. The lysate was clarified using a 45 minutes, $360,000 \mathrm{~g}$ spin in a Ti70 rotor. The supernatant was incubated with 1-mL Streptactin sepharose beads (IBA Life Sciences, Goettingen, Germany) for 1 hour. Beads were washed with $40 \mathrm{~mL}$ of lysis buffer followed by $30 \mathrm{~mL}$ labeling buffer ( $50 \mathrm{mM}$ HEPES pH 7.4, $300 \mathrm{mM} \mathrm{NaCl}, 10 \mathrm{mM} \mathrm{MgCl}, 1 \mathrm{mM}$ EGTA, 10\% glycerol, $1 \mathrm{mM}$ DTT). Beads were then collected and incubated with purified Sfp 
phosphopantetheinyl transferase and an LD655 dye functionalized with CoA (Lumidyne, New York, USA) at room temperature for 30 minutes. Beads were washed with $30-\mathrm{mL}$ labeling buffer. If proteins were to be kinase or phosphatase treated, they were additionally washed with $30 \mathrm{~mL}$ kinase (20 mM HEPES pH 7.5, 300mM NaCl, $10 \mathrm{mM} \mathrm{MgCl} 2,200 \mu \mathrm{M}$ ATP, $10 \%$ glycerol, $1 \mathrm{mM} \mathrm{DTT}$ ) or phosphatase (20 mM HEPES pH 7.5, 300mM NaCl, $1 \mathrm{mM} \mathrm{MnSO} 4$, $10 \%$ glycerol, $1 \mathrm{mM}$ DTT) buffer. Protein was eluted in $1 \mathrm{~mL}$ fractions in its final buffer supplemented with $10 \mathrm{mM}$ desthiobiotin and concentrated using Amicon Ultra 30K concentrators. For kinase and phosphatase treatment, $5 \mu \mathrm{L}$ of caseine kinase 2 (New England Biolabs, Massachusetts, USA) or $2.5 \mu \mathrm{L} \lambda$ phosphatase (New England Biolabs, Massachusetts, USA) was added per $50 \mu \mathrm{L}$ concentrated protein, respectively, and the samples were incubated at $30^{\circ} \mathrm{C}$ for 1 hour. Final protein concentration was measured using Bradford reagent, and aliquots were snap frozen in liquid nitrogen.

\section{In vitro transcription and RNA labeling}

For in vitro transcription of long viral RNA, the region of interest was first PCR amplified from a plasmid (N plasmid was a generous gift from the Krogan lab [1], $5^{\prime}$ UTR plasmid was a generous gift from the Gladfelter lab [56], and SARS-CoV-2 cDNA plasmid was a generous gift of the Thiel lab [55]) using a forward primer with a T7 polymerase binding site (TAATACGACTCACTATAGGG). The amplified DNA was tested for purity on a $0.8 \%$ agarose gel and cleaned up using GlycoBlue and ethanol precipitation. RNA was generated using the HiScribe T7 Quick kit (New England Biolabs, Massachusetts, USA) and extracted using trizol and isopropanol precipitation. RNA was Cy3 labeled using a Label IT kit (Mirus Bio, Wisconsin, USA), and RNA purity was verified using a $0.8 \%$ agarose gel. All RNA structure predictions were done on the RNAfold server $[57,58]$.

\section{Sample preparation and microscopy}

Purified protein and RNA samples were diluted into the imaging buffer (50 mM HEPES pH 7.4, $150 \mathrm{mM} \mathrm{NaCl}, 5 \mathrm{mM} \mathrm{MgCl}$, $1 \mathrm{mM} \mathrm{EGTA}, 1 \mathrm{mM} \mathrm{DTT}, 1 \%$ pluronic) to their final concentration and introduced into the flow chamber. Samples were settled onto the coverslip for 25 minutes before imaging. We confirmed that all of the condensates were settled to the surface within 25 minutes, as we did not observe an increase in the number of condensates per viewing area of the coverslip, and we could not detect freely diffusing condensates in the flow chamber after 25 minutes. Different buffers were used for phosphatase-treated (50 mM HEPES pH 7.4, $150 \mathrm{mM} \mathrm{NaCl}, 0.5 \mathrm{mM}$ MnSO4, $1 \mathrm{mM}$ DTT, $1 \%$ pluronic) and kinase-treated (20 mM HEPES pH 7.5, $150 \mathrm{mM} \mathrm{NaCl}, 5 \mathrm{mM} \mathrm{MgCl}_{2}, 100 \mu \mathrm{M}$ ATP, $1 \mathrm{mM} \mathrm{DTT}, 1 \%$ pluronic) samples.

Imaging was performed using a custom-built fiber-coupled Nikon Ti-E Eclipse microscope equipped with an objective-type total internal reflection fluorescence (TIRF) illuminator and 100X 1.49 N.A. Plan Apo oil immersion objective (Nikon, New York, USA). The samples were excited in near-TIRF using 561 and $633 \mathrm{~nm}$ laser beams (Coherent, California, USA). The fluorescent signal was detected by Andor Ixon electron-multiplying CCD (EMCCD) camera $(512 \times 512$ pixels). The effective pixel size was $160 \mathrm{~nm}$ after magnification. 10 single-frame images were acquired for each condition in each replicate.

\section{Image analysis}

To calculate the saturation concentration $\left(\mathrm{c}_{\mathrm{sat}}\right)$, the area of each condensate was quantified with Fiji using the Phansalkar function with a 30-pixel radius and a minimum condensate size of 10 pixels. The volume of the condensates was estimated from 2D projections by taking the 
semi-principal axis in the z-plane as the geometric average of semi-principal axes in the $\mathrm{xy}$ plane. The total volume of the condensates settled per micron squared on the coverslip was quantified. Conditions that resulted in measurable condensate volumes were fit to linear regression in Origin. The $\mathrm{x}$-intercept of the linear regression represents $\mathrm{c}_{\mathrm{sat}}$, the minimum protein concentration that results in condensate formation. The aspect ratio was calculated for individual condensates in Fiji using the Phansalkar function with a 30-pixel radius and a minimum condensate size of 10 pixels. To measure fusion times, condensates were visualized as they settled on the imaging surface from 5 to 25 minutes after mixing. Movies were recorded at 5 frames per second. Fusion times were calculated as the time between the last frame where 2 condensates appear separated (i.e., no overlap) and the first frame where the fused condensate appears nearly spherical (aspect ratio $=1.1)$.

\section{In vitro FRAP}

In vitro FRAP assays were performed with a Zeiss 880 Confocal Laser Scanning Microscope equipped with a 100×, 1.4 NA oil immersion objective. Samples were prepared as described above. All in vitro FRAP experiments used the $488 \mathrm{~nm}$ laser at $100 \%$ for bleaching conditions. For $\mathrm{N}$-polyC at $150 \mathrm{mM} \mathrm{NaCl}, 5$ bleaching iterations were used, and images were taken every 2 seconds for 232 seconds. For viral RNA at $150 \mathrm{mM} \mathrm{NaCl}, 100$ bleaching iterations were used, and images were taken every 10 seconds for 8 minutes. For the experiments conducted at 50 $\mathrm{mM} \mathrm{NaCl}$, droplets containing polyC RNA or viral RNA were bleached with 20 iterations, and images were taken every 5 seconds for 5 minutes. For droplets containing $\mathrm{N}$ protein only, 20 bleaching iterations were used, and images were collected every 2 seconds for 6.5 minutes. All data were acquired using Zeiss Zen 2.3 SP1 FP3 (black) (64bit) Version 14.0.20.201. Data were background corrected, converted to normalized intensity, and fit to an exponential decay function in Origin.

\section{MS}

The cross-linking analysis was performed as described by McGilvray and colleagues [90] with deviations outlined here. $15 \mu \mathrm{L} 90 \mu \mathrm{M} \mathrm{N}$ protein in the labeling buffer was diluted $1: 3 \mathrm{v} / \mathrm{v}$ into either water or labeling buffer. The diluted protein formed condensates in $100 \mathrm{mM} \mathrm{NaCl}$ in the final buffer, but not in the labeling buffer that contains $300 \mathrm{mM} \mathrm{NaCl}$. Isotopically coded light (H12) and heavy (D12) BS3 (bis(sulfosuccinimidyl)suberate) cross-linkers (Creative Molecules, California, USA) were immediately added to the diluted solution. Final concentration of BS3 was $0.8 \mathrm{mM}$ for $100 \mathrm{mM} \mathrm{NaCl}$ dilution and $2.5 \mathrm{mM}$ for $300 \mathrm{mM} \mathrm{NaCl}$ dilution. Crosslinking was performed for 30 minutes at room temperature and then quenched with $1 \mathrm{M}$ Tris $\mathrm{pH} 8.0$ buffer. This experiment was performed in duplicate, once with D12-BS3 cross-linking $\mathrm{N}$ protein in condensates and H12-BS3 cross-linking soluble N protein and once with the labels reversed. The cross-linked proteins from both channels were pooled before acetone precipitation. Protein was precipitated with acetone overnight at $-20^{\circ} \mathrm{C}$. Protein was pelleted, the supernatant was removed, and the samples were air-dried for 10 minutes. The pellets were brought up in $8 \mathrm{M}$ urea, reduced with TCEP, alkylated with iodoacetamide, diluted 4-fold, and digested with 2 rounds of trypsin. Peptides were desalted on a C18 MacroTrap column (Michrom Bioresources, California, USA) and fractionated on a Superdex Peptide (GE Life Sciences, Illinois, USA) size exclusion column. Fractions enriched in cross-linked peptides were dried and resuspended in $0.1 \%$ formic acid for MS. Later eluting fractions were used for phosphorylation analysis. Each of the replicates was fractionated by size exclusion chromatography (SEC), and each fraction was injected twice, generating 16 MS files for analysis. 
MS was acquired on an Orbitrap Fusion Lumos coupled with an Easy-Spray nanoelectrospray ion source, a $15 \mathrm{~cm} \times 75 \mu \mathrm{m}$ PepMap $\mathrm{C}_{18}$ column (Thermo Fisher Scientific, Massachusetts, USA) and an M-class NanoAcuity UPLC system (Waters, Massachusetts, USA). Liquid chromatography-mass spectrometry (LC-MS) runs were 90 minutes long. Precursor ions were measured in the Orbitrap at $120 \mathrm{k}$ resolution. Selected precursor ions (triply charged and higher) were isolated, and the product ions were measured in the Orbitrap at $30 \mathrm{k}$ resolution. Samples that were analyzed for phosphorylation were run similarly except only HCD product ions spectra were collected and doubly charge precursors were included.

Cross-linked spectra were identified with Protein Prospector 6.2.23 [91] using the combination of DSS/DSS:2H12 at uncleaved Lys residues and protein N-terminus as the cross-linking reagents. The corresponding light and heavy dead-end modifications, incorrect monoisotopic peak assignment (+1Da neutral loss), $\mathrm{N}$-terminal pyroglutamate formation, methionine oxidation, and acetylation and loss of the protein $\mathrm{N}$-terminal methionine were set as variable modifications with 3 variable modifications per peptide allowed. Trypsin with 2 missed cleavages was the digestion enzyme, and the mass tolerances were 20 and $30 \mathrm{ppm}$ for precursor and product ions. The search database comprised the 14 most abundant proteins (sorted by spectral abundance factor, SAF) found in the linear peptide SEC fractions, alongside a decoy database that was 10 times longer. Cross-link spectral matches were classified at a $1 \%$ false discovery rate (FDR) threshold.

Protein Prospector was used to search for phosphopeptides of the linear peptide fractions using the following parameters: tryptic specificity with 2 missed cleavages, 7 and $15 \mathrm{ppm}$ precursor and product ion tolerances, and carbamidomethyl (C) fixed modification. Variable modifications were as above except that Phospho (STY) was included, and only dead-end cross-link modifications were included. Peptides were reported with a maximum expectation value of 0.001 , and a minimum prospector score of 15 . A site localization in peptide (SLIP) score threshold of 6 was used to determine site localization. All phosphopeptide spectra reported were manually inspected for evidence of correct site assignment. Where $\mathrm{S}$ or $\mathrm{T}$ residues are adjacent, the location of the phosphosite is ambiguous (see S2 Table). All phosphorylation data can be accessed here (or on the MS-Viewer website with search key "jyovxenjny").

A supplemental search of the cross-linked peak lists was made for cross-links that also contained a phosphorylation site. This search was identical to the previous cross-linking searches except that Phospho (ST) was included as a variable modification, and the search was limited to the $\mathrm{N}$ protein sequence. Search results containing a phosphorylation site were manually assessed. Only phosphorylation sites that had been discovered in the phospho search of the linear peptides were considered.

For quantitating the isotopically labeled cross-links, peak areas were measured from the extracted precursor ion chromatograms (XICs) using the small molecule interface of Skyline (v20.1.0.155). A Skyline transition list was generated containing the elemental composition of each distinct peptide pair with both light and heavy BS3 modification and in each charge state detected in the Prospector search. Retention times were present in the transition list to help with peak detection. Peptide level measurements were imported into $\mathrm{R}$ and summarized at the level of unique residue pairs ("cross-links"). For each precursor ion, the $\log _{2}$ ratios of heavy to light peptides were calculated and mean normalized to 0 for each of the 2 biological replicates and then transformed into $\log _{2}$ (water/salt) ratios. Weighted $t$ tests were performed in R.

\section{Drug screening and image processing}

For the FDA-approved drug screen, $75 \mathrm{~mL}$ of $\mathrm{N}$ protein at $16 \mu \mathrm{M}$ was purified from HEK293S GNTI- cells. polyC RNA was obtained from Sigma. The FDA-approved drug library (TargetMol) 
has 1,200 compounds of well-characterized biological activity. A total of $10 \mathrm{mM}$ compounds were stored in $100 \%$ dimethyl sulfoxide (DMSO) in 384-well plates. For screening plates, $20 \mu \mathrm{L}$ imaging buffer (50 mM HEPES pH 7.4, 150 mM NaCl, 5 mM MgCl 2,1 mM EGTA, 1 mM DTT, $1 \%$ pluronic) was aliquoted into 384-well, glass-bottomed plates (Greiner Bio-One, Kremsmunster, Austria) and incubated for 5 minutes. Buffer was removed, and $0.5 \mu \mathrm{L}$ of $2 \mathrm{mM}$ compounds were stamped into 384-well plates with an Analytik-Jena Cybio Well Vario liquid handler. The final concentration of $7.8 \mu \mathrm{M} \mathrm{N}$ protein and $50 \mathrm{ng} / \mu \mathrm{L}$ polyC RNA were added to each plate. Each well contained a $25 \mu \mathrm{L}$ mixture and $40 \mu \mathrm{M}$ compound in the primary screen.

Wells were homogenized with a Bioshake 3000 ELM orbital shaker at 2,400 rpm for $45 \mathrm{sec}-$ onds, and condensates were allowed to settle for 1 hour before imaging. Moreover, 4 images (each $224 \times 167 \mu \mathrm{m}$ ) were taken at 40× with ImageXpress Micro High Content Imaging System (Molecular Devices, California, USA). Images were analyzed with Metamorph Imaging software calculating condensate count and area. The volume of the condensates was calculated as described above. Data were then uploaded to CCD Vault for normalization to DMSO vehicle control wells. Wells that exhibit 3 SDs from the untreated sample and as well as others that produced qualitative morphological changes in $\mathrm{N}$ condensates were selected for dose-response screening. The same $\mathrm{N}$ protein and RNA were tested against candidate drugs using a 10-point serial dilution starting at $40 \mu \mathrm{M}$ using the same procedure. Dose-response curves were generated by fitting to the equation

$$
y(C)=y_{\min }+\frac{\left(y_{\max }-y_{\min }\right)}{1+\left(\frac{C}{E C_{50}}\right)^{n}},
$$

where $C$ is the concentration of the drug, $n$ is the Hill coefficient, $E C_{50}$ is the half-maximal response concentration, and $y$ is either the volume of the $\mathrm{N}$ condensates or the number of $\mathrm{N}$ condensates settled onto per micron squared area on the coverslip.

\section{Dose-response with SARS-CoV-2-infected cells}

Vero-E6 (ATCC, CRL-1586) and Calu-3 cells (ATCC HTB-55) were cultured in high glucose DMEM (Gibco) supplemented with 10\% FBS (R\&D Systems), 1X GlutaMAX (Gibco), and 1X PenStrep (Gibco) at $37^{\circ} \mathrm{C}$ and $5 \% \mathrm{CO}_{2}$. For screening selected drugs against infected cells, 2,500 Vero-E6 (12 $\mu \mathrm{L} /$ well) or 10,000 Calu-3 (12 $\mu \mathrm{L} /$ well) were seeded in 384-well white optical bottom tissue culture plates (Nunc) with the Multidrop Combi liquid handling instrument (Thermo Fisher Scientific). Cells were allowed to recover for 24 hours for Vero-E6 and 48 hours for Calu- 3 at $37^{\circ} \mathrm{C}$ and $5 \% \mathrm{CO}_{2}$. Dose responses were generated by diluting the compounds using a Cybio Well Vario liquid handler (Analytik Jena, Jena, Germany), leading to a final concentration of DMSO at $0.4 \%$ in the assay plate $(\mathrm{v} / \mathrm{v})$. Cells were incubated at $37^{\circ} \mathrm{C}$ and $5 \% \mathrm{CO}_{2}$ for 1 hour before infection. The viral inoculum was prepared such that the final multiplicity of infection (MOI) was 0.05 upon addition of $6 \mu \mathrm{L} /$ well viral inoculum. After complete CPE was observed in DMSO-treated, infected wells (72 hours postinfection (hpi) for Vero-E6 and 96 hpi for Calu-3), the plates were developed with the CellTiter-Glo 2.0 reagent (Promega, Wisconsin, USA) according to the manufacturer's instructions. For Vero-E6, the reagent was diluted 1:1 (v/v) in PBS. Luminescence of developed plates was read on a Spectramax L (Molecular Devices). Each plate contained 24 wells uninfected/DMSO treated cells (100\% CPE inhibition) and 24 wells infected/DMSO treated cells ( $0 \%$ CPE inhibition). Average values from those wells were used to normalize data and determine \% CPE inhibition for each compound well. To determine the cytotoxicity of the compounds, the same protocol was used but with 6- $\mu \mathrm{L}$ growth media added instead of viral inoculum. The data were plotted and analyzed in Origin and fit to the dose-response function above. 


\section{Dose-response determination by $\mathrm{TCID}_{50}$ assay}

Vero-E6 cells were plated at 10,000 cells per well in Vero growth medium as above in 96-well plates and allowed to recover for 24 hours. Drug treatments were prepared in the same medium at $1.33 \times$ of final concentration and $0.53 \% \mathrm{v} / \mathrm{v}$ DMSO. Growth medium was removed from cells and replaced with 150- $\mu \mathrm{L}$ medium with drug treatment and incubated for 1 hour. Virus in $50-\mu \mathrm{L}$ medium was added to each well to produce a final MOI of 0.05 , final drug concentrations as indicated, and $0.4 \% \mathrm{v} / \mathrm{v}$ DMSO per well. Vehicle-only treatment was used as a positive control for productive viral infection and $\mathrm{CPE}$, and remdesivir at $50 \mu \mathrm{M}$ was used as a positive control for viral restriction by drug treatment. Each condition was plated in triplicate. Virus titer following drug treatment was determined by $\mathrm{TCID}_{50}$ assay in Vero-E6 cells. At 24 hours post infection, $100 \mu \mathrm{L}$ of supernatant from drug-treated infected cells was removed from each well and used to prepare a 10-fold dilution series in Vero growth medium. Moreover, $50 \mu \mathrm{L}$ of the dilution series was added to Vero cells in 96-well plates, prepared as above, in $100 \mu \mathrm{L}$ medium. Cells were observed for $\mathrm{CPE}$ for 3 days. $\mathrm{TCID}_{50} / \mathrm{mL}$ results were calculated using the Spearman and Kärber method [92].

\section{HEK293T cell culture and transfection}

HEK293T (RRID: CVCL_0063) cells were cultured in phenol-negative DMEM media supplemented with $10 \% \mathrm{FBS}$ and $1 \% \mathrm{PS}$ at $37^{\circ} \mathrm{C}$ with $5 \% \mathrm{CO}_{2}$. Prior to imaging, cells were transferred to glass-bottomed plates (Nunc Lab-Tek, $0.4 \mathrm{~mL}$ working volume) at approximately $25 \%$ confluence and allowed to recover for 24 hours. Media was exchanged into phenol-negative DMEM media supplemented with $10 \%$ FBS, and cells were transfected with N-GFP, $\mathrm{N} \triangle \mathrm{R} 2$-GFP, or GFP only constructs. For each well, $400 \mathrm{ng}$ of DNA was added to $20 \mu \mathrm{L}$ DMEM media. A total of $1.2 \mu \mathrm{L}$ FuGENE HD transfection reagent (Promega) was added, and the mixture was incubated at room temperature for 15 minutes before being added to the cell culture. Cells were allowed to express the constructs for 4 days. One hour prior to imaging, DRAQ5 stain at 1:1,000 was added to the media.

\section{In vivo imaging and FRAP assays}

In vivo imaging and FRAP measurements were performed with a Zeiss 880 Confocal Laser Scanning Microscope equipped with a 63×, 1.4 NA oil immersion objective. Samples were prepared as described above. All in vivo FRAP experiments used the $488 \mathrm{~nm}$ laser at $100 \%$ for bleaching conditions. Cells expressing N-GFP, $\triangle \mathrm{R} 2$-GFP, or GFP only were bleached with 30 iterations, and images were collected continuously at $6.7 \mathrm{~Hz}$ for 30 seconds. All data were acquired using Zeiss Zen 2.3 SP1 FP3. Data were converted to the normalized intensity and fit to an exponential decay function in Origin.

\section{U2OS cell culture, transfection, and RNA FISH}

U2OS cells stably expressing SARS-CoV-2 N protein with a carboxyl-terminal Clover tag were a gift from the Cleveland lab at the University of California San Diego (UCSD). Cells were cultured in phenol-negative DMEM media supplemented with $10 \% \mathrm{FBS}$ and $1 \% \mathrm{PS}$ at $37^{\circ} \mathrm{C}$ with $5 \% \mathrm{CO}_{2}$. Prior to imaging, cells were transferred to glass-bottomed plates (Nunc Lab-Tek, 0.4 $\mathrm{mL}$ working volume) at approximately $25 \%$ confluence. Cells were transfected with a construct expressing N-MS2 RNA (the N cDNA sequence with 6 upstream stop codons and 3 carboxylterminal MS2 repeats) as described above. Cells were induced with doxycycline at a final concentration of $1,000 \mathrm{ng} / \mathrm{mL}$ and allowed to express for 14 hours. FISH was performed following the Stellaris RNA FISH protocol for adherent cells. Cells were fixed with 3.7\% formaldehyde, 
permeabilized with $70 \%$ ethanol, and incubated in the dark at $37^{\circ} \mathrm{C}$ overnight with hybridization buffer (Biosearch Technologies, Middlesex, UK) supplemented with 10\% deionized formamide and either $125 \mathrm{nM}$ Cy3-(d)T20 oligonucleotides (Gene Link, Florida, USA) or $1 \mu \mathrm{M}$ Cy3-MS2 probe (IDT (Iowa, USA), sequence AGGCAATTAGGTACCTTAGG) [19]. Cells were washed with wash buffer A (Biosearch Technologies, Middlesex, UK) for 30 minutes, then incubated with DRAQ5 1:1,000 in wash buffer A for 30 minutes and exchanged into wash buffer B (Biosearch Technologies) before imaging.

\section{Supporting information}

S1 Fig. Gel filtration and EMSA analysis of the WT N protein purified from HEK293S GNTI- cells. (A) The coomassie-stained denaturing gel of the $\mathrm{N}$ protein purified from affinity chromatography. (B) UV absorbance of the $\mathrm{N}$ protein purified from affinity chromatography shows no evidence for the presence of contaminating nucleic acids. (C) UV absorbance of protein standards eluting from a gel filtration column. (D) UV absorbance of the $\mathrm{N}$ protein eluting from a gel filtration column. Arrows mark the void volume and expected elution volume for an $\mathrm{N}$ monomer. (E) The coomassie-stained denaturing gel of the eluents from the gel filtration column. The yellow arrowhead shows the expected molecular weight of full-length $\mathrm{N}$ protein. (F) EMSA using no RNA, $10 \mathrm{nM} 0-5 \mathrm{~kb}$ viral RNA, and $50 \mathrm{ng} / \mu \mathrm{L}$ polyC RNA and decreasing concentration of $\mathrm{N}$ protein. The protein was labeled with LD655. RNA was labeled with $\mathrm{Cy} 3$. Arrowheads indicate the minimum protein concentration for each condition with a noticeable signal in the protein gel. EMSA, electrophoresis mobility shift assay; N, nucleocapsid; WT, wild-type.

S2 Fig. RNA substrates do not form condensates in the absence of $\mathbf{N}$ protein. (A) An agarose gel picture of $0-5 \mathrm{~kb}$ viral RNA and polyC RNA substrates. The gel was stained with GelRed (left), and the RNA substrates were labeled with $\mathrm{Cy} 3$ (right). The ladder corresponds to the length of double-stranded DNA. Estimated lengths of $0-5 \mathrm{~kb}$ viral RNA and polyC RNA are $5 \mathrm{~kb}$ and $2 \mathrm{~kb}$, respectively. (B) Representative pictures show that $18 \mathrm{nM} \mathrm{0-5} \mathrm{kb}$ viral RNA and $50 \mathrm{ng} / \mu \mathrm{L}$ polyC RNA do not form condensates in the absence of $\mathrm{N}$ protein. The assay was performed in $150 \mathrm{mM} \mathrm{NaCl}$. (C) Two-color imaging shows colocalization of LD655-labeled $\mathrm{N}$ protein and Cy3-labeled polyC RNA in condensates. N, nucleocapsid.

S3 Fig. FRAP analysis of $\mathrm{N}$-polyC condensates in vitro. (A) Control experiments show changes in the fluorescent signal of $\mathrm{N}$ and polyC without photobleaching. (B) The changes in the integrated fluorescent intensities of regions highlighted with yellow and red rectangles in (A). (C) The maximum fractional recovery of $\mathrm{N}$ and polyC in condensates after photobleaching $(n=36$, mean $\pm \mathrm{SD})$. The center and edges of the box represent the median with the first and third quartiles. The $p$-value was calculated from a 2-tailed $t$ test. Data underlying this figure can be found in S1 Data. FRAP, fluorescence recovery after photobleaching; N, nucleocapsid.

(TIF)

S4 Fig. The $\mathrm{N}$ protein forms asymmetric condensates with viral RNA. (A) Structure prediction of each section of SARS-CoV-2 genomic RNA. (B) The formation of asymmetric $\mathrm{N}$ condensates under different viral RNA concentrations. The $\mathrm{N}$ protein concentration was set to $18.5 \mu \mathrm{M}$. (C) Structure prediction of viral RNA (left) and the formation of asymmetric N condensates under different RNA concentrations (right). The N RNA is the $1.3 \mathrm{~kb}$ long genomic RNA fragment that encodes the SARS-CoV- $2 \mathrm{~N}$ protein. The $5^{\prime}$ UTR RNA is the first 1,000 
bases of the SARS-CoV-2 genome. The N protein concentration was set to $18.5 \mu \mathrm{M}$. (D) The distribution of aspect ratios of individual condensates formed with different RNA substrates. The $\mathrm{N}$ protein concentration was set to $18.5 \mu \mathrm{M}$, and RNA concentration was set to $50 \mathrm{ng} / \mu \mathrm{L}$ for RNA homopolymers and $18 \mathrm{nM}$ for $0-5 \mathrm{~kb}$ viral RNA. The center and edges of the box represent the median with the first and third quartiles. $p$-Values are calculated from 2 -tailed $t$ tests. Data underlying this figure can be found in S1 Data. IVT, in vitro transcribed; N, nucleocapsid; SARS-CoV-2, Severe Acute Respiratory Syndrome Coronavirus 2; UTR, untranslated region.

(TIF)

S5 Fig. Condensates formed by the $\mathrm{N}$ protein and viral RNA do not fuse or change shape but are dissolved at higher salt. (A) Condensates formed by the $\mathrm{N}$ protein with in vitro transcribed N RNA or the $5^{\prime}$ UTR of the viral RNA are not sensitive to an increase of temperature to $37^{\circ} \mathrm{C}$. (B) Condensates formed by the $\mathrm{N}$ protein with $5^{\prime}$ UTR of viral RNA do not change shape over 24 hours. (C) Condensates formed by $11.5 \mu \mathrm{M}$ N protein and $36 \mathrm{nM} 5^{\prime}$ UTR RNA are dissolved in the presence of $260 \mathrm{mM} \mathrm{NaCl}$. (D) Condensates formed by $18.5 \mu \mathrm{M} \mathrm{N}$ protein

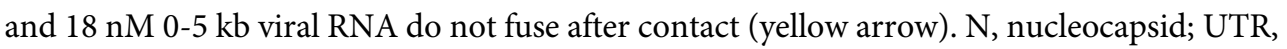
untranslated region.

(TIF)

S6 Fig. FRAP analysis of $\mathrm{N}$ and 0-5 kb viral RNA condensates in vitro. (A) Control experiments show snapshots of LD655-labeled $\mathrm{N}$ and Cy3-labeled 0-5 kb viral RNA without photobleaching. (B) The changes in the integrated fluorescent intensities of the regions that are highlighted with yellow and red rectangles in (A). Data underlying this figure can be found in S1 Data. FRAP, fluorescence recovery after photobleaching; N, nucleocapsid. (TIF)

S7 Fig. Interactions between $\mathrm{N}$ proteins and between $\mathrm{N}$ and G3BP1. (A) In an initial qualitative experiment, pairwise interactions were detected by CLMS at $300 \mathrm{mM}$ salt. Blue dots depict the positions of lysine residues. Lines depict a unique cross-link detected. The regions of $\mathrm{N}$ protein interactions flank the CTD. (B) Volcano plot of the quantitative CLMS data comparing the condensate and no condensate condition. Opaque data points have a $p$-value below 0.05 , and transparent data points have a $p$-value greater than 0.05 . Green represents unique crosslinks that are enriched in the condensate condition. The yellow markers represent the K169-K65 and K169 (phosS176)-K65 cross-links. (C) The structure of the CTD of the SARS-CoV-2 N protein was plotted with BioRender (PDB 6WJI [89]). Because the $\mathrm{N}$ terminus and carboxyl terminus of the protomers are positioned away from each other, R1 and R2 within the same dimer are unlikely to interact with each other. (D) MS identified that the RNA binding domain of the stress granule protein G3BP1 interacts with the R2 region of N. Data underlying this figure can be found in S1 Table. CLMS, cross-linking mass spectrometry; CTD, carboxyl-terminal domain; MS, mass spectrometry; N, nucleocapsid; SARS-CoV-2, Severe Acute Respiratory Syndrome Coronavirus 2.

(TIF)

S8 Fig. Purification and characterization of the deletion mutants. (A) Denaturing gel pictures of purified WT and deletion mutants of N protein in the presence and absence of kinase and phosphatase treatment (see Methods). The gels were stained with Coomassie. Yellow arrowheads highlight a reduction in molecular weight upon treatment with $\lambda$ phosphatase. (B) UV absorbance of the $\Delta \mathrm{R} 2$ mutant eluting from a gel filtration column. UV absorbance of WT $\mathrm{N}$ under the same experimental conditions is shown in a dashed red curve for comparison. (C) EMSA gels using no RNA, $10 \mathrm{nM} 0-5 \mathrm{~kb}$ viral RNA, or $50 \mathrm{ng} / \mu \mathrm{L}$ polyC RNA and decreasing 
concentration of the $\Delta \mathrm{R} 2$ mutant. The protein was labeled with LD655. RNA was labeled with $\mathrm{Cy} 3$. Arrows indicate the minimum protein concentration for each condition with a noticeable signal in the protein gel. EMSA, electrophoresis mobility shift assay; MS, mass spectrometry; $\mathrm{N}$, nucleocapsid; WT, wild-type.

(TIF)

S9 Fig. The in vitro phase separation behavior of the deletion mutants of the $\mathrm{N}$ protein. (A) Example pictures show that the $\mathrm{N}$ deletion mutants, except $\Delta \mathrm{R} 2$, form spherical condensates with polyC RNA under different RNA concentrations. The N protein concentration was set to $18.5 \mu \mathrm{M}$. (B) The total volume of N-RNA condensates settled per micron squared area on the coverslip (mean $\pm \mathrm{SD} ; n=20,2$ technical replicates) exhibits a reentrant behavior under an increasing RNA concentration. (C) Example pictures show that the $\mathrm{N}$ deletion mutants, except $\Delta \mathrm{R} 2$, form spherical condensates with polyC RNA under different protein concentrations. The polyC RNA concentration was set to $50 \mathrm{ng} / \mu \mathrm{L}$. (D) The total volume of N-RNA condensates settled per micron squared area on the coverslip (mean \pm SD; $n=20,2$ technical replicates) under an increasing protein concentration. (E) Phase separation of truncated $\mathrm{N}$

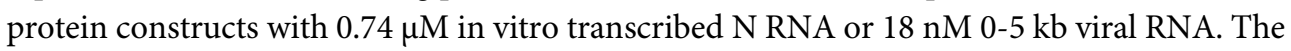
protein concentration was set to $18.5 \mu \mathrm{M}$. Data underlying this figure can be found in S1 Data. $\mathrm{N}$, nucleocapsid.

(TIF)

S10 Fig. Phase separation of truncated $N$ proteins under different phosphorylation conditions in vitro. (A) Images of condensates formed by untreated and dephosphorylated $\Delta S R$ in the presence of $50 \mathrm{ng} / \mu \mathrm{L}$ polyC RNA. (B) The total volume of the condensates settled per micron squared area on the coverslip as a function of $\Delta \mathrm{SR}$ concentration (mean $\pm \mathrm{SD}, n=20$ with 2 technical replicates). (C) Images of condensates formed by untreated and dephosphorylated $\Delta \mathrm{R} 1$ in the presence of $50 \mathrm{ng} / \mu \mathrm{L}$ polyC RNA. (D) The total volume of the condensates settled per micron squared area on the coverslip as a function of $\Delta \mathrm{R} 1$ concentration (mean $\pm \mathrm{SD}, n=20$ with 2 technical replicates). (E) Full-length $\mathrm{N}$ protein forms asymmetric condensates with $0.74 \mu \mathrm{M}$ in vitro transcribed $\mathrm{N}$ RNA before and after phosphorylation and dephosphorylation. The protein concentration was set to $35 \mu \mathrm{M}$. Data underlying this figure can be found in S1 Data. N, nucleocapsid.

(TIF)

S11 Fig. Phase separation of the $\mathrm{N}$ protein under drug treatment. (A) Example pictures show phase separation of $7.8 \mu \mathrm{M} \mathrm{N}$ protein and $50 \mathrm{ng} / \mu \mathrm{L}$ polyC RNA at different drug concentrations. (B) The percent change on the number (blue) and total volume (black) of N-polyC condensates settled per micron squared area on the coverslip under different drug concentrations (mean $\pm \mathrm{SD}, n=8$ with 2 technical replicates). (C) Example pictures show phase separation of $57.6 \mu \mathrm{M}$ LD655-labeled $\mathrm{N}$ protein and $1.5 \mu \mathrm{M}$ Cy3-labeled in vitro transcribed N RNA in the presence of different drug treatments. The concentration of drugs was set to $40 \mu \mathrm{M}$. (D) Condensates formed in the presence of $57.6 \mu \mathrm{M} \mathrm{N}$ protein and 1.5 $\mu \mathrm{M} \mathrm{N}$ RNA form threadlike filaments at high nilotinib concentrations. Data underlying this figure can be found in S1 Data. N, nucleocapsid.

S12 Fig. The viability of SARS-CoV-2-infected cells under drug treatment. (A) Percent $\mathrm{CPE}$ inhibition (black, mean \pm SD, 2 technical replicates) and cell viability (blue) of SARS-CoV-2-infected Calu-3 cells treated with serial dilutions of drugs. Solid curves represent a fit to a dose-response equation to determine $\mathrm{EC}_{50}$. (B) Viral titer in uninfected and SARS-CoV2-infected Vero-E6 cells as measured by a $\mathrm{TCID}_{50}$ assay. Infected cells were treated with 
DMSO (negative control) and $50 \mu \mathrm{M}$ remdesivir (positive control). Data underlying this figure can be found in S1 Data. CPE, cytopathic effect; SARS-CoV-2, Severe Acute Respiratory Syndrome Coronavirus 2; TCID, tissue culture infectious dose.

(TIF)

S13 Fig. Dynamics of N protein in cells. (A) Representative FRAP imaging of HEK293T cells with high expression of N-GFP or $\triangle \mathrm{R} 2-\mathrm{GFP}$. Circles show the photobleached and control (not bleached) regions. (B) Fluorescence recovery signals of the $\mathrm{N}$ protein in the bleached versus the control regions. The solid curve represents a single exponential fit to reveal the recovery lifetime ( $\tau, \pm 95 \%$ confidence interval). (C) The distribution of fluorescence recovery lifetimes of cells expressing N-GFP or $\triangle \mathrm{R} 2$-GFP and exhibiting either puncta or high expression (from left to right, $n=28,34,15$, and 28). The center and edges of the box represent the median with the first and third quartiles. The $p$-values were calculated from a 2 -tailed $t$ test. (D) The maximum fractional recovery after photobleaching of cells expressing N-GFP or $\triangle$ R2-GFP and exhibiting either puncta or high expression (from left to right, $n=28,34,15$, and 28). The center and edges of the box represent the median with the first and third quartiles. The $p$-values were calculated from a 2-tailed $t$ test. (E) U2OS cells stably expressing N-Clover form condensates in the cytoplasm. Cy3-d(T)20 FISH probe targeting the polyA tails of RNA transcripts is uniformly distributed in cells exhibiting $\mathrm{N}$ condensates with (left) or without (right) expression of N-MS2 ( $N=40$ cells, 2 technical replicates). Inset scale bar is $2 \mu \mathrm{m}$. Data underlying this figure can be found in S1 Data. FRAP, fluorescence recovery after photobleaching; N, nucleocapsid.

S14 Fig. Dynamics of $\mathrm{N}$ protein in $50 \mathrm{mM} \mathrm{NaCl}$ in vitro. (A) Representative FRAP imaging of $\mathrm{N}$ protein only, or in the presence of polyC or $0-5 \mathrm{~kb}$ viral RNA. The concentrations of $\mathrm{N}$, polyC, and $0-5 \mathrm{~kb}$ viral RNA were kept at $24 \mu \mathrm{M}, 50 \mathrm{ng} / \mu \mathrm{L}$, and $18 \mathrm{nM}$, respectively. Rectangles highlight the photobleached area. (B) Fluorescence recovery signals of the N protein and RNA in the bleached versus the control regions. Solid curves represent a single exponential fit to reveal the recovery lifetime ( $\tau, \pm 95 \%$ confidence interval). (C) The distribution of fluorescence recovery lifetimes of the condensates (from left to right, $n=20,17,23,28$, and 28). The center and edges of the box represent the median with the first and third quartiles. The $p$-values were calculated from a 2 -tailed $t$ test. (D) The maximum fractional recovery after photobleaching (from left to right, $n=20,17,23,28$, and 28). The center and edges of the box represent the median with the first and third quartiles. The $p$-values were calculated from a 2-tailed $t$ test. Data underlying this figure can be found in S1 Data. FRAP, fluorescence recovery after photobleaching; N, nucleocapsid.

\section{S15 Fig. In vitro phase separation of WT N and deletion mutants in the presence of a} crowding agent. (A) (Left) Images of the LD655-labeled N protein in the presence of 10\% PEG and $150 \mathrm{mM} \mathrm{NaCl}$. The assays were performed in the absence of RNA. (Right) The total volume of $\mathrm{N}$ condensates settled per micron squared area on the coverslip (mean $\pm \mathrm{SD}, n=20$ with 2 technical replicates). A linear fit (solid line) reveals $c_{\text {sat }}( \pm S E)$. (B) Images of the condensates formed in the presence of LD655-labeled WT N protein before or after phosphatase and kinase treatments in the presence of $10 \%$ PEG and $150 \mathrm{mM} \mathrm{NaCl}$ (C) Images of the LD655-labeled truncated $\mathrm{N}$ protein mutants in the presence of $10 \% \mathrm{PEG}$ and $150 \mathrm{mM} \mathrm{NaCl}$. The protein concentration was set at $3 \mu \mathrm{M}$. Assays were performed in the absence of RNA. Data underlying this figure can be found in S1 Data. N, nucleocapsid; WT, wild-type. (TIF) 
S1 Table. Cross-link fold changes with $p$-values less than 0.05 upon phase separation. The cross-link (xlink) position indicates the amino acid number of the $\mathrm{N}$ protein sequence. The K169-K65 peptide is phosphorylated at S176. N, nucleocapsid.

(DOCX)

S2 Table. A compilation of the SARS-CoV-2 N protein phosphosites identified by MS. (A) The coverage map and phosphorylation sites for the $\mathrm{N}$ protein detected in proteomics experiments. Text in red indicates peptide regions that were not detected; green highlight indicates an unambiguous phosphorylation site; and yellow highlight indicates an ambiguous phosphorylation site. (B) Each site identified by our study is characterized as being unambiguously or ambiguously localized based on manual inspection of the product ion series. See Methods for the full protein sequence and a link to supporting evidence. S176 is a phosphorylation site identified on a cross-linked peptide. MS, mass spectrometry; N, nucleocapsid. (DOCX)

S3 Table. Proteins identified by MS in the high salt sample of $\mathrm{N}$ protein from human cells. (A) The proteins were ranked by SAF. These protein sequences were included in the CLMS search. Asterisks indicate exogenous proteins. (B) Cross-links between N and the G3BP1 and G3BP2 stress granule proteins identified in the qualitative CLMS experiment ranked by an SVM score. Values are frequency of detection (2 conditions with 2 replicates each). Xlink position indicates the amino acid number of the given protein sequence. SVM indicates the confidence that the cross-link is correctly identified. CLMS, cross-linking mass spectrometry; MS, mass spectrometry; N, nucleocapsid; SAF, spectral abundance factor; SVM, support vector machine.

(DOCX)

S4 Table. Quantitative analysis of $\mathrm{N}$ condensates. The parameters of fitting to a doseresponse equation in the presence and absence of polyC RNA in response to increasing concentrations of salt or nelfinavir mesylate. $\mathrm{N}$, nucleocapsid.

(DOCX)

S1 Data. Numerical data underlying main and Supporting information figures. Figs 1C$1 \mathrm{H}, 2 \mathrm{C}, 2 \mathrm{D}, 4 \mathrm{D}, 4 \mathrm{~F}, 5 \mathrm{~B}, 5 \mathrm{C}$, and 6C-6E and S3B, S3C, S4D, S6B, S9B, S9D, S10B, S10D, S11B, S12A, S12B, S13B-S3D, S14B-S14D, and S15A Figs. Figs are presented in separate Excel sheets that are combined into a single Excel file. The numerical data include all replicates. (XLSX)

S1 Raw Images. Uncropped gel images underlying S1 A, S1E and S1F, S2A, and S8AC Figs. (PDF)

\section{Acknowledgments}

We thank John T. Canty, Ruensern Tan, Jonathan Fernandes, and other members of the Yildiz laboratory for helpful discussions, the UC Berkeley Biological Imaging Facility for use of their confocal FRAP microscope, Denise Schichnes (UC Berkeley Biological Imaging Facility) for FRAP advice and training, Thomas Graham (UC Berkeley) for advice and reagents for in vitro transcription, Kathy Li (UCSF) for assisting with CLMS sample preparation, Nevan Krogan (UCSF), Amy Gladfelter (UNC) and Volker Thiel (Univ. Bern) for providing the plasmids, Don Cleveland (UCSD) for providing the U2OS N-Clover cell line, the UC Berkeley MacroLab for TEV protease and competent cells, and the UC Berkeley Cell Culture Facility for HEK293S GNTI- and HEK293T cells. 


\section{Disclaimers}

The content is solely the responsibility of the authors and does not represent the official views of funding institutions.

\section{Author Contributions}

Conceptualization: Amanda Jack, Luke S. Ferro, Sarah Stanley, Julia Schaletzky, Ahmet Yildiz.

Data curation: Amanda Jack, Luke S. Ferro, Michael J. Trnka, Eddie Wehri, Xammy Nguyenla, Douglas Fox, Sarah Stanley, Julia Schaletzky.

Formal analysis: Amanda Jack, Luke S. Ferro, Michael J. Trnka, Eddie Wehri, Amrut Nadgir, Xammy Nguyenla, Douglas Fox, Julia Schaletzky.

Funding acquisition: Amanda Jack, Luke S. Ferro, Sarah Stanley, Julia Schaletzky, Ahmet Yildiz.

Investigation: Amanda Jack, Xammy Nguyenla, Sarah Stanley, Ahmet Yildiz.

Methodology: Luke S. Ferro, Michael J. Trnka, Eddie Wehri, Amrut Nadgir, Xammy Nguyenla, Douglas Fox, Julia Schaletzky.

Project administration: Ahmet Yildiz.

Resources: Amanda Jack.

Software: Eddie Wehri, Amrut Nadgir, Katelyn Costa.

Supervision: Ahmet Yildiz.

Validation: Amanda Jack, Eddie Wehri.

Visualization: Amanda Jack, Katelyn Costa.

Writing - original draft: Amanda Jack, Luke S. Ferro, Michael J. Trnka, Julia Schaletzky, Ahmet Yildiz.

\section{References}

1. Gordon DE, Jang GM, Bouhaddou M, Xu J, Obernier K, White KM, et al. A SARS-CoV-2 protein interaction map reveals targets for drug repurposing. Nature. 2020; 583(7816):459-68. https://doi.org/10. 1038/s41586-020-2286-9 PMID: 32353859

2. Shang J, Ye G, Shi K, Wan Y, Luo C, Aihara H, et al. Structural basis of receptor recognition by SARSCoV-2. Nature. 2020; 581(7807):221-4. https://doi.org/10.1038/s41586-020-2179-y PMID: 32225175

3. Chan KK, Dorosky D, Sharma P, Abbasi SA, Dye JM, Kranz DM, et al. Engineering human ACE2 to optimize binding to the spike protein of SARS coronavirus 2. Science. 2020; 369(6508):1261-5. https:// doi.org/10.1126/science.abc0870 PMID: 32753553

4. Hoffmann M, Kleine-Weber H, Schroeder S, Krüger N, Herrler T, Erichsen S, et al. SARS-CoV-2 cell entry depends on ACE2 and TMPRSS2 and is blocked by a clinically proven protease inhibitor. Cell. 2020; 181(2):271-80. https://doi.org/10.1016/j.cell.2020.02.052 PMID: 32142651

5. Mulligan MJ, Lyke KE, Kitchin N, Absalon J, Gurtman A, Lockhart S, et al. Phase I/II study of COVID-19 RNA vaccine BNT162b1 in adults. Nature. 2020; 586(7830):589-93. https://doi.org/10.1038/s41586020-2639-4 PMID: 32785213

6. Sahin U, Muik A, Derhovanessian E, Vogler I, Kranz LM, Vormehr M, et al. COVID-19 vaccine BNT162b1 elicits human antibody and T(H)1 T cell responses. Nature. 2020; 586(7830):594-9. https:// doi.org/10.1038/s41586-020-2814-7 PMID: 32998157

7. Yao H, Song Y, Chen Y, Wu N, Xu J, Sun C, et al. Molecular architecture of the SARS-CoV-2 virus. Cell. 2020; 183(3):730-8. https://doi.org/10.1016/j.cell.2020.09.018 PMID: 32979942 
8. Carlson CR, Asfaha JB, Ghent CM, Howard CJ, Hartooni N, Safari M, et al. Phosphoregulation of phase separation by the SARS-CoV-2 N protein suggests a biophysical basis for its dual functions. Mol Cell. 2020; 80(6):1092-103. https://doi.org/10.1016/j.molcel.2020.11.025 PMID: 33248025

9. Laude H, Masters PS. The Coronavirus Nucleocapsid Protein. In: Siddell SG, editor. The Coronaviridae. Boston, MA: Springer US; 1995. p. 141-63.

10. Bouhaddou M, Memon D, Meyer B, White KM, Rezelj VV, Correa Marrero M, et al. The global phosphorylation landscape of SARS-CoV-2 infection. Cell. 2020; 182(3):685-712. https://doi.org/10.1016/j. cell.2020.06.034 PMID: 32645325

11. Cong $\mathrm{Y}$, Ulasli M, Schepers $\mathrm{H}$, Mauthe M, V'Kovski P, Kriegenburg F, et al. Nucleocapsid protein recruitment to replication-transcription complexes plays a crucial role in coronaviral life cycle. J Virol. 2020; 94(4):e01925-19. https://doi.org/10.1128/JVI.01925-19 PMID: 31776274

12. Snijder EJ, Limpens R, de Wilde AH, de Jong AWM, Zevenhoven-Dobbe JC, Maier HJ, et al. A unifying structural and functional model of the coronavirus replication organelle: Tracking down RNA synthesis. PLoS Biol. 2020; 18(6):e3000715. https://doi.org/10.1371/journal.pbio.3000715 PMID: 32511245

13. McBride R, van Zyl M, Fielding $B C$. The coronavirus nucleocapsid is a multifunctional protein. Viruses. 2014; 6(8):2991-3018. https://doi.org/10.3390/v6082991 PMID: 25105276

14. Wolff G, Limpens R, Zevenhoven-Dobbe JC, Laugks U, Zheng S, de Jong AWM, et al. A molecular pore spans the double membrane of the coronavirus replication organelle. Science. 2020; 369 (6509):1395-8. https://doi.org/10.1126/science.abd3629 PMID: 32763915

15. Klein S, Cortese M, Winter SL, Wachsmuth-Melm M, Neufeldt CJ, Cerikan B, et al. SARS-CoV-2 structure and replication characterized by in situ cryo-electron tomography. Nat Commun. 2020; 11(1):5885 https://doi.org/10.1038/s41467-020-19619-7 PMID: 33208793

16. Banani SF, Lee HO, Hyman AA, Rosen MK. Biomolecular condensates: organizers of cellular biochemistry. Nat Rev Mol Cell Biol. 2017; 18(5):285-98. https://doi.org/10.1038/nrm.2017.7 PMID: 28225081

17. Hyman AA, Weber CA, Julicher F. Liquid-liquid phase separation in biology. Annu Rev Cell Dev Biol 2014; 30:39-58. https://doi.org/10.1146/annurev-cellbio-100913-013325 PMID: 25288112

18. Guseva S, Milles S, Jensen MR, Salvi N, Kleman JP, Maurin D, et al. Measles virus nucleo- and phosphoproteins form liquid-like phase-separated compartments that promote nucleocapsid assembly. Sci Adv. 2020; 6(14):eaaz7095. https://doi.org/10.1126/sciadv.aaz7095 PMID: 32270045

19. Jain A, Vale RD. RNA phase transitions in repeat expansion disorders. Nature. 2017; 546(7657):243-7. https://doi.org/10.1038/nature22386 PMID: 28562589

20. Sanders DW, Kedersha N, Lee DSW, Strom AR, Drake V, Riback JA, et al. Competing protein-RNA interaction networks control multiphase intracellular organization. Cell. 2020; 181(2):306-324. https:// doi.org/10.1016/j.cell.2020.03.050 PMID: 32302570

21. Riback JA, Zhu L, Ferrolino MC, Tolbert M, Mitrea DM, Sanders DW, et al. Composition-dependent thermodynamics of intracellular phase separation. Nature. 2020; 581(7807):209-14. https://doi.org/10. 1038/s41586-020-2256-2 PMID: 32405004

22. Siu YL, Teoh KT, Lo J, Chan CM, Kien F, Escriou N, et al. The M, E, and N structural proteins of the severe acute respiratory syndrome coronavirus are required for efficient assembly, trafficking, and release of virus-like particles. J Virol. 2008; 82(22):11318-30. https://doi.org/10.1128/JVI.01052-08 PMID: 18753196

23. Heinrich BS, Maliga Z, Stein DA, Hyman AA, Whelan SPJ. Phase transitions drive the formation of vesicular stomatitis virus replication compartments. mBio. 2018; 9(5):e02290-17. https://doi.org/10. 1128/mBio.02290-17 PMID: 30181255

24. Nikolic J, Le Bars R, Lama Z, Scrima N, Lagaudrière-Gesbert C, Gaudin Y, et al. Negri bodies are viral factories with properties of liquid organelles. Nat Commun. 2017; 8(1):58. https://doi.org/10.1038/ s41467-017-00102-9 PMID: 28680096

25. Monette A, Niu M, Chen L, Rao S, Gorelick RJ, Mouland AJ. Pan-retroviral nucleocapsid-mediated phase separation regulates genomic RNA positioning and trafficking. Cell Rep. 2020; 31(3):107520. https://doi.org/10.1016/j.celrep.2020.03.084 PMID: 32320662

26. Ye Q, West AMV, Silletti S, Corbett KD. Architecture and self-assembly of the SARS-CoV-2 nucleocapsid protein. Protein Sci. 2020; 29(9):1890-901. https://doi.org/10.1002/pro.3909 PMID: 32654247

27. Chen CY, Chang CK, Chang YW, Sue SC, Bai HI, Riang L, et al. Structure of the SARS coronavirus nucleocapsid protein RNA-binding dimerization domain suggests a mechanism for helical packaging of viral RNA. J Mol Biol. 2007; 368(4):1075-86. https://doi.org/10.1016/j.jmb.2007.02.069 PMID: 17379242

28. Chang CK, Chen CM, Chiang MH, Hsu YL, Huang TH. Transient oligomerization of the SARS-CoV N protein-implication for virus ribonucleoprotein packaging. PLoS ONE. 2013; 8(5):e65045. https://doi. org/10.1371/journal.pone.0065045 PMID: 23717688 
29. Boeynaems S, Holehouse AS, Weinhardt V, Kovacs D, Van Lindt J, Larabell C, et al. Spontaneous driving forces give rise to protein-RNA condensates with coexisting phases and complex material properties. Proc Natl Acad Sci U S A. 2019; 116(16):7889-98. https://doi.org/10.1073/pnas.1821038116 PMID: 30926670

30. Perlmutter JD, Qiao C, Hagan MF. Viral genome structures are optimal for capsid assembly. Elife. 2013; 2:e00632. https://doi.org/10.7554/eLife.00632 PMID: 23795290

31. Cubuk J, Alston JJ, Incicco JJ, Singh S, Stuchell-Brereton MD, Ward MD, et al. The SARS-CoV-2 nucleocapsid protein is dynamic, disordered, and phase separates with RNA. Nat Commun. 2021; 12 (1):1936.

32. Ukmar-Godec T, Hutten S, Grieshop MP, Rezaei-Ghaleh N, Cima-Omori MS, Biernat J, et al. Lysine/ RNA-interactions drive and regulate biomolecular condensation. Nat Commun. 2019; 10(1):2909. https://doi.org/10.1038/s41467-019-10792-y PMID: 31266957

33. King $O D$, Gitler AD, Shorter J. The tip of the iceberg: RNA-binding proteins with prion-like domains in neurodegenerative disease. Brain Res. 2012; 1462:61-80. https://doi.org/10.1016/j.brainres.2012.01. 016 PMID: 22445064

34. Hurst KR, Kuo L, Koetzner CA, Ye R, Hsue B, Masters PS. A major determinant for membrane protein interaction localizes to the carboxy-terminal domain of the mouse coronavirus nucleocapsid protein. $J$ Virol. 2005; 79(21):13285-97. https://doi.org/10.1128/JVI.79.21.13285-13297.2005 PMID: 16227251

35. Kuo L, Hurst-Hess KR, Koetzner CA, Masters PS. Analyses of coronavirus assembly interactions with interspecies membrane and nucleocapsid protein chimeras. J Virol. 2016; 90(9):4357-68. https://doi. org/10.1128/JVI.03212-15 PMID: 26889024

36. Chen H, Cui Y, Han X, Hu W, Sun M, Zhang Y, et al. Liquid-liquid phase separation by SARS-CoV-2 nucleocapsid protein and RNA. Cell Res. 2020; 30(12):1143-5. https://doi.org/10.1038/s41422-02000408-2 PMID: 32901111

37. Chang CK, Hsu YL, Chang YH, Chao FA, Wu MC, Huang YS, et al. Multiple nucleic acid binding sites and intrinsic disorder of severe acute respiratory syndrome coronavirus nucleocapsid protein: implications for ribonucleocapsid protein packaging. J Virol. 2009; 83(5):2255-64. https://doi.org/10.1128/JVI. 02001-08 PMID: 19052082

38. Lu S, Ye Q, Singh D, Cao Y, Diedrich JK, Yates JR, et al. The SARS-CoV-2 nucleocapsid phosphoprotein forms mutually exclusive condensates with RNA and the membrane-associated M protein. Nat Commun. 2021; 12(1):502. https://doi.org/10.1038/s41467-020-20768-y PMID: 33479198

39. Kang S, Yang M, Hong Z, Zhang L, Huang Z, Chen X, et al. Crystal structure of SARS-CoV-2 nucleocapsid protein RNA binding domain reveals potential unique drug targeting sites. Acta Pharm Sin B. 2020; 10(7):1228-38. https://doi.org/10.1016/j.apsb.2020.04.009 PMID: 32363136

40. Dinesh DC, Chalupska D, Silhan J, Koutna E, Nencka R, Veverka V, et al. Structural basis of RNA recognition by the SARS-CoV-2 nucleocapsid phosphoprotein. PLoS Pathog. 2020; 16(12):e1009100. https://doi.org/10.1371/journal.ppat.1009100 PMID: 33264373

41. Bar-On YM, Flamholz A, Phillips R, Milo R. SARS-CoV-2 (COVID-19) by the numbers. elife. 2020; 9: e57309. https://doi.org/10.7554/eLife.57309 PMID: 32228860

42. Jawerth LM, ljavi M, Ruer M, Saha S, Jahnel M, Hyman AA, et al. Salt-dependent rheology and surface tension of protein condensates using optical traps. Phys Rev Lett. 2018; 121(25):258101. https://doi. org/10.1103/PhysRevLett.121.258101 PMID: 30608810

43. Boyko S, Qi X, Chen TH, Surewicz K, Surewicz WK. Liquid-liquid phase separation of tau protein: The crucial role of electrostatic interactions. J Biol Chem. 2019; 294(29):11054-9. https://doi.org/10.1074/ jbc.AC119.009198 PMID: 31097543

44. Alberti S, Saha S, Woodruff JB, Franzmann TM, Wang J, Hyman AA. A user's guide for phase separation assays with purified proteins. J Mol Biol. 2018; 430(23):4806-20. https://doi.org/10.1016/j.jmb. 2018.06.038 PMID: 29944854

45. Alberti S, Gladfelter A, Mittag T. Considerations and challenges in studying liquid-liquid phase separation and biomolecular condensates. Cell. 2019; 176(3):419-34. https://doi.org/10.1016/j.cell.2018.12. 035 PMID: 30682370

46. Savastano A, Ibáñez de Opakua A, Rankovic M, Zweckstetter M. Nucleocapsid protein of SARS-CoV-2 phase separates into RNA-rich polymerase-containing condensates. Nat Commun. 2020; 11(1):6041. https://doi.org/10.1038/s41467-020-19843-1 PMID: 33247108

47. Banerjee PR, Milin AN, Moosa MM, Onuchic PL, Deniz AA. Reentrant phase transition drives dynamic substructure formation in ribonucleoprotein droplets. Angew Chem Int Ed Engl. 2017; 56(38):11354-9. https://doi.org/10.1002/anie.201703191 PMID: 28556382 
48. Sanders DW, Kedersha N, Lee DSW, Strom AR, Drake V, Riback JA, et al. Competing protein-RNA interaction networks control multiphase intracellular organization. Cell. 2020; 181(2):306-24. https:// doi.org/10.1016/j.cell.2020.03.050 PMID: 32302570

49. Van Treeck B, Protter DSW, Matheny T, Khong A, Link CD, Parker R. RNA self-assembly contributes to stress granule formation and defining the stress granule transcriptome. Proc Natl Acad Sci U S A. 2018; 115(11):2734-9. https://doi.org/10.1073/pnas.1800038115 PMID: 29483269

50. Ray S, Bandaria JN, Qureshi MH, Yildiz A, Balci H. G-quadruplex formation in telomeres enhances POT1/TPP1 protection against RPA binding. Proc Natl Acad Sci U S A. 2014; 111(8):2990-5. https:// doi.org/10.1073/pnas.1321436111 PMID: 24516170

51. Conforti R, Ma Y, Morel Y, Paturel C, Terme M, Viaud S, et al. Opposing effects of toll-like receptor (TLR3) signaling in tumors can be therapeutically uncoupled to optimize the anticancer efficacy of TLR3 ligands. Cancer Res. 2010; 70(2):490-500. https://doi.org/10.1158/0008-5472.CAN-09-1890 PMID: 20068181

52. Ma W, Zhen G, Xie W, Mayr C. Unstructured mRNAs form multivalent RNA-RNA interactions to generate TIS granule networks. bioRxiv. 2020. https://doi.org/10.1101/2020.02.14.949503

53. Ma W, Mayr C. A membraneless organelle associated with the endoplasmic reticulum enables 3 'UTRmediated protein-protein interactions. Cell. 2018; 175(6):1492-506. https://doi.org/10.1016/j.cell.2018. 10.007 PMID: 30449617

54. Perdikari TM, Murthy AC, Ryan VH, Watters S, Naik MT, Fawzi NL. SARS-CoV-2 nucleocapsid protein phase-separates with RNA and with human hnRNPs. EMBO J. 2020; 39(24):e106478. https://doi.org/ 10.15252/embj.2020106478 PMID: 33200826

55. Thi Nhu Thao T, Labroussaa F, Ebert N, V'Kovski P, Stalder H, Portmann J, et al. Rapid reconstruction of SARS-CoV-2 using a synthetic genomics platform. Nature. 2020; 582(7813):561-5. https://doi.org/ 10.1038/s41586-020-2294-9 PMID: 32365353

56. Iserman C, Roden CA, Boerneke MA, Sealfon RSG, McLaughlin GA, Jungreis I, et al. Genomic RNA elements drive phase separation of the SARS-CoV-2 nucleocapsid. Mol Cell. 2020; 80(6):1078-91. https://doi.org/10.1016/j.molcel.2020.11.041 PMID: 33290746

57. Gruber AR, Lorenz R, Bernhart SH, Neuböck R, Hofacker IL. The Vienna RNA Websuite. Nucleic Acids Res. 2008; 36:W70-W4. https://doi.org/10.1093/nar/gkn188 PMID: 18424795

58. Lorenz R, Bernhart SH, Höner Zu Siederdissen C, Tafer H, Flamm C, Stadler PF, et al. ViennaRNA Package 2.0. Algorithms Mol Biol. 2011; 6:26. https://doi.org/10.1186/1748-7188-6-26 PMID: 22115189

59. Chu F, Thornton DT, Nguyen HT. Chemical cross-linking in the structural analysis of protein assemblies. Methods. 2018; 144:53-63. https://doi.org/10.1016/j.ymeth.2018.05.023 PMID: 29857191

60. Chen ZA, Rappsilber J. Protein dynamics in solution by quantitative crosslinking/mass spectrometry. Trends Biochem Sci. 2018; 43(11):908-20. https://doi.org/10.1016/j.tibs.2018.09.003 PMID: 30318267

61. Davidson AD, Williamson MK, Lewis S, Shoemark D, Carroll MW, Heesom KJ, et al. Characterisation of the transcriptome and proteome of SARS-CoV-2 reveals a cell passage induced in-frame deletion of the furin-like cleavage site from the spike glycoprotein. Genome Med. 2020; 12(68). https://doi.org/10. 1186/s13073-020-00763-0 PMID: 32723359

62. Supekar NT, Shajahan A, Gleinich AS, Rouhani D, Heiss C, Azadi P. SARS-CoV-2 Nucleocapsid protein is decorated with multiple $\mathrm{N}$ - and O-glycans. bioRxiv. 2020. https://doi.org/10.1101/2020.08.26. 269043

63. Wang J, Shi C, Xu Q, Yin H. SARS-CoV-2 nucleocapsid protein undergoes liquid-liquid phase separation into stress granules through its N-terminal intrinsically disordered region. Cell Discov. 2021; 7(1):5. https://doi.org/10.1038/s41421-020-00240-3 PMID: 33479219

64. Wu CH, Chen PJ, Yeh SH. Nucleocapsid phosphorylation and RNA helicase DDX1 recruitment enables coronavirus transition from discontinuous to continuous transcription. Cell Host Microbe. 2014; 16 (4):462-72. https://doi.org/10.1016/j.chom.2014.09.009 PMID: 25299332

65. Wu CH, Yeh SH, Tsay YG, Shieh YH, Kao CL, Chen YS, et al. Glycogen synthase kinase-3 regulates the phosphorylation of severe acute respiratory syndrome coronavirus nucleocapsid protein and viral replication. J Biol Chem. 2009; 284(8):5229-39. https://doi.org/10.1074/jbc.M805747200 PMID: 19106108

66. Wheeler RJ, Lee HO, Poser I, Pal A, Doeleman T, Kishigami S, et al. Small molecules for modulating protein driven liquid-liquid phase separation in treating neurodegenerative disease. bioRxiv. 2019. https://doi.org/10.1101/721001

67. Patel A, Lee HO, Jawerth L, Maharana S, Jahnel M, Hein MY, et al. A liquid-to-solid phase transition of the ALS protein FUS accelerated by disease mutation. Cell. 2015; 162(5):1066-77. https://doi.org/10. 1016/j.cell.2015.07.047 PMID: 26317470 
68. Nguyenla X, Wehri E, Van Dis E, Biering SB, Yamashiro LH, Stroumza J, et al. Discovery of SARSCoV-2 antiviral synergy between remdesivir and approved drugs in human lung cells. bioRxiv. 2020. https://doi.org/10.1101/2020.09.18.302398.

69. Pruijssers AJ, George AS, Schäfer A, Leist SR, Gralinksi LE, Dinnon KH III, et al. Remdesivir inhibits SARS-CoV-2 in human lung cells and chimeric SARS-CoV expressing the SARS-CoV-2 RNA polymerase in mice. Cell Rep. 2020; 32(3):107940. https://doi.org/10.1016/j.celrep.2020.107940 PMID: 32668216

70. Nabeel-Shah S, Lee H, Ahmed N, Marcon E, Farhangmehr S, Pu S, et al. SARS-CoV-2 Nucleocapsid protein attenuates stress granule formation and alters gene expression via direct interaction with host mRNAs. bioRxiv. 2020. https://doi.org/10.1101/2020.10.23.342113

71. Roden CA, Dai Y, Seim I, Lee M, Sealfon R, McLaughlin GA, et al. Double-stranded RNA drives SARSCoV-2 nucleocapsid protein to undergo phase separation at specific temperatures. bioRxiv. 2021. https://doi.org/10.1101/2021.06.14.448452 PMID: 34159327

72. Zhao H, Wu D, Nguyen A, Li Y, Adão RC, Valkov E, et al. Energetic and structural features of SARSCoV-2 N-protein co-assemblies with nucleic acids. iScience. 2021; 24(6):102523. https://doi.org/10. 1016/j.isci.2021.102523 PMID: 33997662

73. Tayeb-Fligelman E, Cheng X, Tai C, Bowler JT, Griner S, Sawaya MR, et al. Inhibition of amyloid formation of the Nucleoprotein of SARS-CoV-2. bioRxiv. 2021. https://doi.org/10.1101/2021.03.05.434000 PMID: 33688654

74. Caruso IP, dos Santos Almeida V, Juliani do Amaral M, de Andrade GC, de Araújo GR, de Araújo TS, et al. Structure insights, thermodynamic profiles, dsDNA melting activity, and liquid-liquid phase separation of the SARS-CoV-2 nucleocapsid N-terminal domain binding to DNA. bioRxiv. 2021. https://doi.org/ 10.1101/2021.07.21.453232

75. Langdon EM, Qiu Y, Ghanbari Niaki A, McLaughlin GA, Weidmann CA, Gerbich TM, et al. mRNA structure determines specificity of a polyQ-driven phase separation. Science. 2018; 360(6391):922-7. https://doi.org/10.1126/science.aar7432 PMID: 29650703

76. He R, Dobie F, Ballantine M, Leeson A, Li Y, Bastien N, et al. Analysis of multimerization of the SARS coronavirus nucleocapsid protein. Biochem Biophys Res Commun. 2004; 316(2):476-83. https://doi. org/10.1016/j.bbrc.2004.02.074 PMID: 15020242

77. Peng TY, Lee KR, Tarn WY. Phosphorylation of the arginine/serine dipeptide-rich motif of the severe acute respiratory syndrome coronavirus nucleocapsid protein modulates its multimerization, translation inhibitory activity and cellular localization. FEBS J. 2008; 275(16):4152-63. https://doi.org/10.1111/j. 1742-4658.2008.06564.x PMID: 18631359

78. Samavarchi-Tehrani P, Abdouni H, Knight JDR, Astori A, Samson R, Lin Z-Y, et al. A SARS-CoV-2 host proximity interactome. bioRxiv. 2020. https://doi.org/10.1101/2020.09.03.282103

79. Wang S, Dai T, Qin Z, Pan T, Chu F, Lou L, et al. Targeting liquid-liquid phase separation of SARSCoV-2 nucleocapsid protein promotes innate antiviral immunity by elevating MAVS activity. Nat Cell Biol. 2021; 23(7):718-32. https://doi.org/10.1038/s41556-021-00710-0 PMID: 34239064

80. Huang W, Ju X, Tian M, Li X, Yu Y, Sun Q, et al. Molecular determinants for regulation of G3BP1/2 phase separation by the SARS-CoV-2 nucleocapsid protein. Cell Discov. 2021; 7(1):69. https://doi.org/ 10.1038/s41421-021-00306-w PMID: 34400613

81. Larson AG, Elnatan D, Keenen MM, Trnka MJ, Johnston JB, Burlingame AL, et al. Liquid droplet formation by HP1alpha suggests a role for phase separation in heterochromatin. Nature. 2017; 547 (7662):236-40. https://doi.org/10.1038/nature22822 PMID: 28636604

82. Strom AR, Emelyanov AV, Mir M, Fyodorov DV, Darzacq X, Karpen GH. Phase separation drives heterochromatin domain formation. Nature. 2017; 547(7662):241-5. https://doi.org/10.1038/nature22989 PMID: 28636597

83. Farag A, Wang $\mathrm{P}$, Ahmed M, Sadek $\mathrm{H}$. Identification of FDA approved drugs targeting COVID-19 virus by structure-based drug repositioning. ChemRxiv. 2020. https://doi.org/10.26434/chemrxiv.12003930. v1

84. Kumar D, Chandel V, Raj S, Rathi B. In silico identification of potent FDA approved drugs against Coronavirus COVID-19 main protease: A drug repurposing approach. Chem Biol Lett 2020; 7(3):10.

85. Li Y, Zhang J, Wang N, Li H, Shi Y, Guo G, et al. Therapeutic drugs targeting 2019-nCoV main protease by high-throughput screening. bioRxiv. 2020. 2020.01.28.922922.

86. Mittal L, Kumari A, Srivastava M, Singh M, Asthana S. Identification of potential molecules against COVID-19 main protease through structure-guided virtual screening approach. J Biomol Struct Dyn. 2021; 39(10):1-19. https://doi.org/10.1080/07391102.2020.1768151 PMID: 32396769 
87. Yamamoto N, Yang R, Yoshinaka Y, Amari S, Nakano T, Cinatl J, et al. HIV protease inhibitor nelfinavir inhibits replication of SARS-associated coronavirus. Biochem Biophys Res Commun. 2004; 318 (3):719-25. https://doi.org/10.1016/j.bbrc.2004.04.083 PMID: 15144898

88. Dyall J, Coleman CM, Hart BJ, Venkataraman T, Holbrook MR, Kindrachuk J, et al. Repurposing of clinically developed drugs for treatment of Middle East respiratory syndrome coronavirus infection. Antimicrob Agents Chemother. 2014; 58(8):4885-93. https://doi.org/10.1128/AAC.03036-14 PMID: 24841273

89. Minasov G, Shuvalova L, Wiersum G, Satchell K.J.F. 2.05 angstrom resolution crystal structure of Cterminal dimerization domain of nucleocapsid phosphoprotein from SARS-CoV-2. 2020; (Center for Structural Genomics of Infectious Diseases (CSGID)). https://doi.org/10.2210/pdb6WJI/pdb

90. McGilvray PT, Anghel SA, Sundaram A, Zhong F, Trnka MJ, Fuller JR, et al. An ER translocon for multipass membrane protein biogenesis. Elife. 2020; 9:e56889. https://doi.org/10.7554/eLife.56889 PMID: 32820719

91. Trnka MJ, Baker PR, Robinson PJ, Burlingame AL, Chalkley RJ. Matching cross-linked peptide spectra: only as good as the worse identification. Mol Cell Proteomics. 2014; 13(2):420-34.

92. Lei C, Yang J, Hu J, Sun X. On the calculation of $\operatorname{TCID}(50)$ for quantitation of virus infectivity. Virol Sin. 2021; 36(1):141-4. https://doi.org/10.1007/s12250-020-00230-5 PMID: 32458296 